\title{
Electrogenic Kinetics of a Mammalian Intestinal Type IIb $\mathrm{Na}+/ \mathrm{Pi}$ Cotransporter
}

\author{
Forster, I C ; Virkki, L V ; Bossi, E ; Murer, H ; Biber, J
}

\begin{abstract}
The kinetics of a type $\mathrm{IIb} \mathrm{Na}(+)$-coupled inorganic phosphate $(\mathrm{Pi})$ cotransporter (NaPi-IIb) cloned from mouse small intestine were studied using the two-electrode voltage clamp applied to Xenopus oocytes. In the steady state, mouse NaPi-IIb showed a curvilinear I-V relationship, with rate-limiting behavior only for depolarizing potentials. The Pi dose dependence was Michaelian, with an apparent affinity constant for $\mathrm{Pi}(\mathrm{Km}(\mathrm{pi}))$ of $10+/-1$ microM: at $-60 \mathrm{mV}$. Unlike for rat NaPi-IIa, (Km(pi)) increased with membrane hyperpolarization, as reported for human NaPi-IIa, flounder NaPi-IIb and zebrafish $\mathrm{NaPi}-\mathrm{IIb} 2$. The apparent affinity constant for $\mathrm{Na}(+)(\mathrm{Km}(\mathrm{na}))$ was $23+/-1 \mathrm{mM}$ : at $-60 \mathrm{mV}$, and the $\mathrm{Na}(+)$ activation was cooperative with a Hill coefficient of approximately 2. Pre-steady-state currents were documented in the absence of $\mathrm{Pi}$ and showed a strong dependence on external $\mathrm{Na}(+)$. The hyperpolarizing shift of the charge distribution midpoint potential was $65 \mathrm{mV} / \log [\mathrm{Na}]$. Approximately half the moveable charge was attributable to the empty carrier. A comparison of the voltage dependence of steady-state Pi-induced current and pre-steady-state charge movement indicated that for $-120 \mathrm{mV}$ $<$ or $=\mathrm{V}<\mathrm{or}=0 \mathrm{mV}$ the voltage dependence of the empty carrier was the main determinant of the curvilinear steady-state cotransport characteristic. External protons partially inhibited NaPi-IIb steadystate activity, independent of the titration of mono- and divalent $\mathrm{Pi}$, and immobilized pre-steady-state charge movements associated with the first $\mathrm{Na}(+)$ binding step.
\end{abstract}

DOI: https://doi.org/10.1007/s00232-006-0016-3

Posted at the Zurich Open Repository and Archive, University of Zurich

ZORA URL: https://doi.org/10.5167/uzh-2749

Journal Article

Published Version

Originally published at:

Forster, I C; Virkki, L V; Bossi, E; Murer, H; Biber, J (2006). Electrogenic Kinetics of a Mammalian Intestinal Type IIb Na+/Pi Cotransporter. Journal of Membrane Biology, 212(3):177-190.

DOI: https://doi.org/10.1007/s00232-006-0016-3 


\title{
Electrogenic Kinetics of a Mammalian Intestinal Type IIb Na ${ }^{+} / \mathbf{P}_{\mathbf{i}}$ Cotransporter
}

\author{
Ian C. Forster ${ }^{1}$, Leila Virkki ${ }^{1}$, Elena Bossi ${ }^{2}$, Heini Murer ${ }^{1}$, Jürg Biber ${ }^{1}$ \\ ${ }^{1}$ Institute of Physiology and Center for Integrative Human Physiology, University of Zurich, Zurich, Switzerland \\ ${ }^{2}$ Department of Structural and Functional Biology, University of Insubria, Varese, Italy
}

Received: 4 May 2006/Revised: 8 June 2006;

\begin{abstract}
The kinetics of a type IIb $\mathrm{Na}^{+}$-coupled inorganic phosphate $\left(\mathrm{P}_{\mathrm{i}}\right)$ cotransporter $(\mathrm{NaPi}-\mathrm{II} b)$ cloned from mouse small intestine were studied using the two-electrode voltage clamp applied to Xenopus oocytes. In the steady state, mouse NaPi-IIb showed a curvilinear $I-V$ relationship, with rate-limiting behavior only for depolarizing potentials. The $\mathrm{P}_{\mathrm{i}}$ dose dependence was Michaelian, with an apparent affinity constant for $\mathrm{P}_{\mathrm{i}}\left(K_{\mathrm{m}}{ }^{\mathrm{P}_{\mathrm{i}}}\right)$ of $10 \pm 1 \mu \mathrm{M}$ at $-60 \mathrm{mV}$. Unlike for rat NaPi-IIa, $K_{\mathrm{m}}{ }^{\mathrm{P}_{i}}$ increased with membrane hyperpolarization, as reported for human NaPi-IIa, flounder NaPi-IIb and zebrafish NaPi-IIb2. The apparent affinity constant for $\mathrm{Na}^{+}\left(K_{\mathrm{m}}{ }^{\mathrm{Na}}\right)$ was $23 \pm 1 \mathrm{~mm}$ at $-60 \mathrm{mV}$, and the $\mathrm{Na}^{+}$activation was cooperative with a Hill coefficient of approximately 2 . Pre-steady-state currents were documented in the absence of $\mathrm{P}_{\mathrm{i}}$ and showed a strong dependence on external $\mathrm{Na}^{+}$. The hyperpolarizing shift of the charge distribution midpoint potential was $65 \mathrm{mV} / \log [\mathrm{Na}]$. Approximately half the moveable charge was attributable to the empty carrier. A comparison of the voltage dependence of steady-state $\mathrm{P}_{\mathrm{i}}$-induced current and pre-steady-state charge movement indicated that for $-120 \mathrm{~m} V \leq V \leq 0 \mathrm{~m} V$ the voltage dependence of the empty carrier was the main determinant of the curvilinear steady-state cotransport characteristic. External protons partially inhibited $\mathrm{NaPi}-\mathrm{II} b$ steadystate activity, independent of the titration of monoand divalent $\mathrm{P}_{\mathrm{i}}$, and immobilized pre-steady-state charge movements associated with the first $\mathrm{Na}^{+}$ binding step.
\end{abstract}

Key words: NaPi-IIb - Electrogenic kinetics Phosphate oocyte - Electrophysiology

Correspondence to: Ian C. Forster; email: Iforster@access.unizh.ch

\section{Introduction}

Sodium-dependent cotransport of inorganic phosphate $\left(\mathrm{P}_{\mathrm{i}}\right)$ in mammals is mediated by three types of membrane transport proteins that display a high specificity for $\mathrm{P}_{\mathrm{i}}$ as their preferred substrate. They utilize the free energy established by the $\mathrm{Na}^{+}$ electrochemical gradient to mediate uphill $\mathrm{P}_{\mathrm{i}}$ translocation across the cell membrane. These cotransporters are distinguished by their molecular composition and tissue expression and have been designated types I, II and III. ${ }^{1}$ Type II and type III $\mathrm{Na}^{+} / \mathbf{P}_{\mathrm{i}}$ cotransporters have high apparent affinities for $\mathrm{P}_{\mathrm{i}}$, typically in the range $10-50 \mu \mathrm{M}$, and are important for maintaining $\mathrm{P}_{\mathrm{i}}$ homeostasis. Type $\mathrm{I}$ transporters exhibit approximately 10 -fold lower apparent affinity for $\mathrm{P}_{\mathrm{i}}$, and their physiological role in $\mathrm{P}_{\mathrm{i}}$ homeostasis is less clear (for review, see Murer et al., 2000; Werner \& Kinne, 2001; Hediger et al., 2004).

Type II $\mathrm{Na}^{+} / \mathrm{P}_{\mathrm{i}}$ cotransporters represent the broadest class, having been cloned and characterized from a number of mammalian as well as nonmammalian species (for review, see Werner, Dehmelt \& Nalbant, 1998; Werner \& Kinne, 2001; Murer, Forster \& Biber, 2004). They have been further subdivided into three subtypes, designated NaPi-IIa, $\mathrm{NaPi}-\mathrm{IIb}$ and $\mathrm{NaPi}-\mathrm{II}$, based on sequence analyses (see Fig. 1). Both NaPi-IIa and NaPi-IIb are electrogenic and preferentially transport divalent $P_{i}$ with a $3: 1 \mathrm{Na}^{+}: P_{i}$ stoichiometry (Forster, Loo \& Eskandari, 1999; Virkki et al., 2005b). The renal cotransporter NaPi-IIc (Segawa et al., 2002) possesses overall $\sim 50 \%$ similarity to NaPi-IIa and NaPi-IIb at

\footnotetext{
1 These proteins originate from three distinct solute carrier gene families SLC17 (type I, e.g., NPT1), SLC34 (type II, e.g., NaPi-II) and SLC20 (type III, e.g., Pit1/2) according to the Hugo gene classification for nomenclature (Hediger et al., 2004)
} 


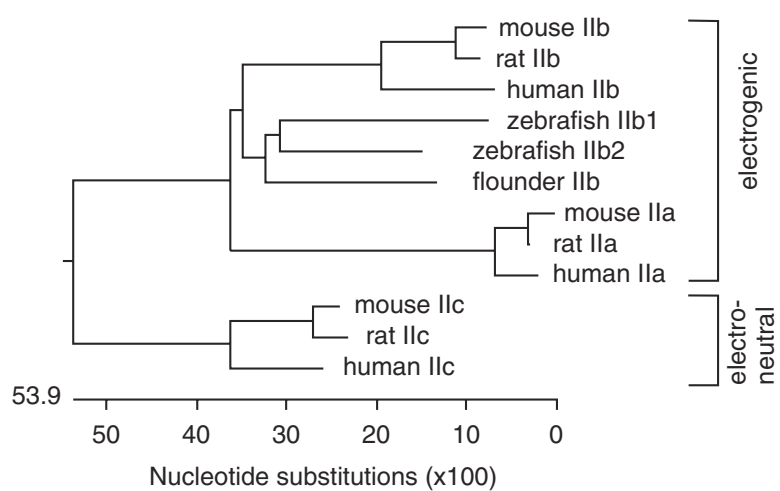

Fig. 1. Dendrogram of selected members of the type II $\mathrm{Na}^{+} / \mathrm{P}_{\mathrm{i}}$ cotransporter family. Amino acid sequences of mammalian and fish NaPi-II proteins were aligned using ClustalW (Chenna et al. 2003). Percent divergence is indicated by the summed horizontal lengths of line segments between labels.

the amino acid level. However, it differs significantly from other identified members of the type II family by having no detectable electrogenicity (Segawa et al., 2002; Ohkido et al., 2003; Bacconi et al., 2005), which is also consistent with its $2: 1 \mathrm{Na}^{+}: \mathrm{P}_{\mathrm{i}}$ stoichiometry (Bacconi et al., 2005). Although NaPi-IIa is primarily expressed in the brush border membrane of mammalian proximal tubule in the kidney, where it mediates renal $P_{i}$ reabsorption (Beck et al., 1998), it is also found in brain (Hisano et al., 1997) and in bone osteoclasts (Gupta et al., 2001; Lundquist, Biber \& Murer, unpublished data), although its function in these latter organs is less well defined. NaPi-IIa isoforms have been extensively characterized by electrophysiology and tracer uptake (Busch et al., 1994; Forster et al., 1998, 1999; Virkki et al., 2005b).

In contrast to the IIa and IIc isoforms, which so far have been found only in mammals, type $\mathrm{IIb} \mathrm{Na}{ }^{+} / \mathrm{P}_{i}$ cotransporters are found in many vertebrate subgroups (bird, teleost, amphibian). Furthermore, unlike $\mathrm{NaPi}-\mathrm{IIa}$ and $\mathrm{NaPi}$-IIc isoforms that are predominantly expressed in the mammalian kidney, NaPi-IIb has a wide tissue distribution and mediates regulated $P_{i}$ uptake in several organs. For example, in the intestine, $\mathrm{NaPi}$-IIb mediates $\mathrm{P}_{\mathrm{i}}$ absorption from the diet (Hilfiker et al., 1998; Radanovic et al., 2005); in the liver, it mediates $P_{i}$ reabsorption from the primary hepatic bile (Frei et al., 2005); and it has been localized in the mouse epididymis, where it may play a role in sperm maturation (Xu et al., 2003). Although NaPi-IIb has not been found in the mammalian kidney (Hilfiker et al., 1998), it is abundantly expressed in teleost kidney (and other organs) (Elger et al., 1998; Graham et al., 2003), where it subserves both reabsorptive as well as secretory functions (Werner \& Kinne, 2001). Kinetically, at least two features distinguish mammalian $\mathrm{NaPi}$-IIb from NaPi-IIa: higher apparent substrate affinity and less sensitivity to changes in external $\mathrm{pH}$ (Hilfiker et al., 1998; Xu et al., 2002; Frei et al., 2005).
Several studies on mammalian NaPi-IIb isoforms (Hilfiker et al., 1998; Feild et al., 1999; Xu et al., 2002; Radanovic, Murer \& Biber, 2003) have relied on radiotracer uptake assays to characterize the transport kinetics and have not taken into account membrane potential as a kinetic determinant. In contrast, a number of detailed studies on teleost $\mathrm{NaPi}$-IIb isoforms have been made by means of electrophysiology (e.g., Forster et al., 1997; Nalbant et al., 1999; Graham et al., 2003; L. V. Virkki, H. Murer \& I. C. Forster, 2006a,b). To address the deficit with respect to the mammalian NaPi-IIb isoforms, we undertook a detailed study of the voltagedependent kinetics of the wild-type mammalian $\mathrm{NaPi}-\mathrm{IIb}$, cloned from mouse kidney (Hilfiker et al., 1998) and expressed in Xenopus oocytes. Our findings revealed significant differences in the voltage-dependent kinetics between mammalian and teleost isoforms. These differences may prove useful for ongoing structure-function studies to aid identification of functionally important parts of the protein (Forster et al., 2002a; Virkki, Murer \& Forster, 2006a,b).

\section{Materials and methods}

\section{REAGENTS AND SOLUTIONS}

All standard reagents were obtained from either Sigma or Fluka (Buchs, Switzerland). The solution compositions (in $\mathrm{mm}$ ) were as follows:

1. Oocyte incubation (modified Barth's solution): $\mathrm{NaCl}(88), \mathrm{KCl}$ (1), $\mathrm{CaCl}_{2}(0.41), \mathrm{MgSO}_{4}(0.82), \mathrm{NaHCO}_{3}$ (2.5), $\mathrm{Ca}\left(\mathrm{NO}_{3}\right)_{2}$ and 4-(2-hydroxyethyl)-1-piperazineethanesulfonic acid (HEPES, 7.5), adjusted to $\mathrm{pH} 7.6$ with TRIS and supplemented with antibiotics (10 mg/l gentamycin, streptomycin)

2. Control superfusate (ND100): $\mathrm{NaCl}(100), \mathrm{KCl}(2), \mathrm{CaCl}_{2}$ (1.8), $\mathrm{MgCl}_{2}$ (1) and HEPES (5), adjusted to desired $\mathrm{pH}$ with TRIS

3. Control superfusate (NDX): as for ND100 but with choline chloride to replace $100-\mathrm{X} \%$ of the $100 \mathrm{~mm} \mathrm{NaCl}$ and adjusted to desired $\mathrm{pH}$ with TRIS

4. Substrate test solutions: $P_{i}$ was added to control superfusate from $1 \mathrm{M} \mathrm{K}_{2} \mathrm{HPO}_{4}$ and $\mathrm{KH}_{2} \mathrm{PO}_{4}$ stocks that were mixed to give the required $\mathrm{pH}$

\section{Oocyte Handling}

The procedures for oocyte preparation and cRNA injection have been described in detail (e.g., Virkki et al., 2005b). Oocytes were injected with either $50 \mathrm{nl}$ of water or $50 \mathrm{nl}$ of water containing $10 \mathrm{ng}$ of cRNA. Oocytes were incubated in modified Barth's solution, and experiments were performed 3-4 days after injection.

\section{Electrophysiology}

The standard two-electrode voltage-clamp technique was used, as previously described (Forster et al., 1998). Data were acquired online using pClamp v. 8.2 and Digidata $1200 \mathrm{~A}$ hardware (Molecular Devices, Sunnyvale, CA). All experiments were 
performed at $20-22^{\circ} \mathrm{C}$ using a cooled recording chamber. Steadystate current-voltage $(I-V)$ curves were obtained by applying a series of voltage steps of $150 \mathrm{~ms}$ duration from $V_{\mathrm{h}}=-60 \mathrm{~m} V$ to the test potential. This same voltage step protocol was used to obtain pre-steady-state relaxations, except that the low-pass filter setting was increased (typically to $0.5 \mathrm{kHz}$ ). In each case, the sampling rate exceeded the Nyquist frequency. All experiments were performed on oocytes from at least two donor frogs to confirm reproducibility.

\section{Data AnAlysis}

\section{Steady-State Substrate Dependence}

Steady-state substrate activation parameters were obtained by fitting the modified Hill equation (equation 1, below) to the doseresponse data for the $\mathrm{P}_{\mathrm{i}}$-induced current $\left(I_{\mathrm{P}_{\mathrm{i}}}\right)$, obtained by subtracting records in NDX from those in NDX $+\mathrm{P}_{\mathrm{i}}$;

$$
I_{P_{i}}=I_{P_{i}}{ }^{\max }[S]^{n_{H}} /\left([S]^{n_{H}}+\left(K_{m}^{S}\right)^{n_{H}}\right)
$$

where, $[\mathrm{S}]$ is the concentration (mM) of the substrate $\mathrm{S}, n_{\mathrm{H}}$ is the Hill coefficient, $I_{P_{i}}{ }^{\max }$ is the predicted maximum $\mathrm{P}_{\mathrm{i}}$-induced current and $K_{\mathrm{m}} \mathrm{S}$ is the apparent affinity constant. Curve fitting was performed using Prism v. 3.2 software (Graphpad Software, San Diego, CA).

\section{Pre-Steady-State Relaxation Analysis}

Pre-steady-state relaxations were fit with a single decaying exponential using a Chebychev transform-based algorithm (Molecular Devices). Curve fitting commenced approximately $17 \mathrm{~ms}$ after the voltage step transitions and the fitted curve was extrapolated to the voltage step transition for estimation of the associated charge. For some batches of oocytes, voltage steps to extreme hyperpolarizing and depolarizing potentials induced a slow transient component, indicative of contamination from $\mathrm{Ca}^{2+}$-dependent $\mathrm{Cl}^{-}$currents. This component was eliminated by either linear baseline subtraction or fitting the data to a single exponential commencing well after the NaPi-IIb-related component had relaxed. The fitted curve was numerically integrated to obtain the charge $(Q)$. The voltage dependence of $Q$ was described analytically by fitting the $Q-V$ data with a Boltzmann relation:

$$
Q=Q_{\text {hyp }}+Q_{\text {max }} /\left\{1+\exp \left[-z \mathrm{e}\left(V-V_{0.5}\right) / \mathrm{k} T\right]\right\}
$$

where $Q_{\max }$ is the maximum charge translocated, $Q_{\text {hyp }}$ is the steady-state charge at the hyperpolarizing limit that depends on $V_{\mathrm{h}}$, $V_{0.5}$ is the voltage at which the charge is distributed equally between the depolarizing and hyperpolarizing limits, $z$ is the apparent valency per cotransporter and $\mathrm{e}, \mathrm{k}$ and $T$ have their usual thermodynamic meanings. Data were fit with equation 2 using Prism v. 3.2 software.

\section{Cotransporter Turnover Rate}

Cotransporter turnover rate was estimated from steady-state and pre-steady-state data as follows. The steady-state $\mathrm{P}_{\mathrm{i}}$-induced current at a given voltage for $N$ active cotransporters is given by the following:

$$
I_{P_{i}}=\phi q \mathrm{e} N
$$

where $\phi$ is the turnover rate $\left(\mathrm{s}^{-1}\right), q$ is the number of charges translocated per cycle and e is the electronic charge. If we assume that $z$ (equation 2) is a measure of the effective mobile charge/ cotransporter, we can find $N$ from the following:
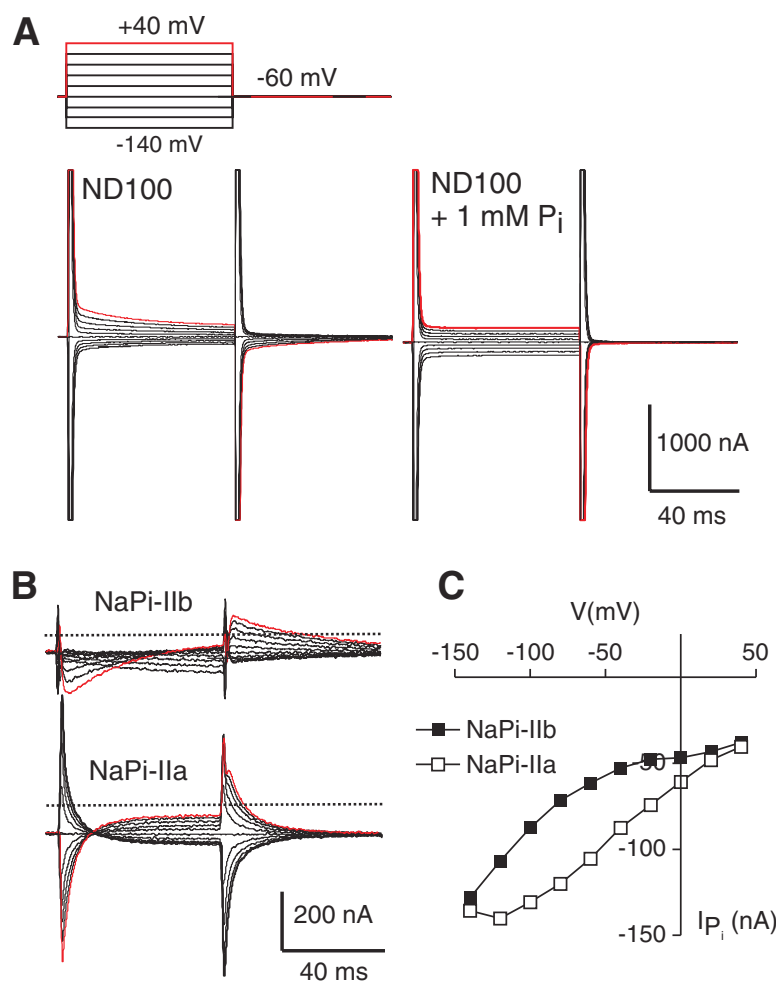

Fig. 2. Basic electrogenic properties of mouse NaPi-IIb. $(A)$ Currents recorded in response to the voltage step protocol shown for a representative oocyte expressing $\mathrm{NaPi}-\mathrm{IIb}$ when superfused in ND100 solution (left) and ND100 $+1 \mathrm{mM} \mathrm{P}_{\mathrm{i}}($ right). $(B)$ Difference between the two data sets in $(A)$ to give the $\mathrm{P}_{\mathrm{i}}$-dependent current for the NaPi-Iib-expressing cell (upper traces). The response of an oocyte expressing rat $\mathrm{NaPi}$-IIa from the same donor frog recorded under the same experimental conditions is also shown (lower traces). Dotted line in each case represents zero current, and red traces indicate the respective responses at $+40 \mathrm{mV}$. (C) Comparison of voltage dependence of steady-state $\mathrm{P}_{\mathrm{i}}$-dependent current $\left(I_{\mathrm{Pi}}\right)$ for the NaPi-IIa- and NaPi-IIb-expressing cells in $(B)$. Data points are joined for visualization.

$$
N=Q_{\max } /(z \mathrm{e})
$$

Elimination of $N$ from equations 3 and 4 and setting $q=1$ (Forster et al., 1999) yields the turnover rate as follows:

$$
\phi=I_{\mathrm{P}_{\mathrm{i}}} z / Q_{\max }
$$

\section{Results}

\section{Voltage Dependence of $\mathrm{P}_{\mathrm{I}}$ and $\mathrm{NA}^{+}$Activation of NaPi-IIb In the Steady STate}

Figure 2A shows original recordings of currents in response to voltage steps in the range -140 to +40 $\mathrm{m} V$ from a holding potential $\left(V_{\mathrm{h}}=-60 \mathrm{~m} V\right)$ applied to a representative oocyte injected with 
mouse NaPi-IIb cRNA before (left traces) and after (right traces) superfusion with $1 \mathrm{~mm} \mathrm{P}_{\mathrm{i}}(\mathrm{pH}$ 7.4) in ND100 solution. In the absence of $P_{i}$, obvious current relaxations were superimposed on the endogenous transient charging of the oocyte capacitance. The relaxations were not observed in noninjected oocytes (data not shown). These so-called pre-steady-state currents were suppressed in the presence of $1 \mathrm{~mm} \mathrm{P}_{\mathrm{i}}$, as we have previously reported for the renal type IIa $\mathrm{Na}^{+} / \mathrm{P}_{\mathrm{i}}$ cotransporter (NaPi-IIa) (Forster et al., 1998) and will be analyzed in more detail in the following section.

The corresponding traces recorded in ND100 were subtracted from those recorded in ND100 $+\mathrm{P}_{i}$ to eliminate endogenous oocyte currents and obtain the $\mathrm{P}_{\mathrm{i}}$-dependent current $\left(I_{\mathrm{P}_{\mathrm{i}}}\right)$ as a function of membrane potential (Fig. 2B, upper traces). This procedure shows more clearly how the NaPi-IIb-associated pre-steady-state relaxations precede the steady-state current. Interestingly, for an oocyte from the same donor frog that expressed the rat renal NaPi-IIa isoform, the relaxations were significantly faster under the same experimental conditions (Fig. 2B, lower traces). The data also show that for these representative oocytes $I_{\mathrm{P}_{\mathrm{i}}}$ at the holding potential $\left(V_{\mathrm{h}}\right)=-60 \mathrm{~m} V$ for NaPi-IIb was smaller than that for NaPi-IIa. This result was not atypical because during routine testing for expression at $V_{\mathrm{h}}=-50$ $\mathrm{m} V$ we consistently observed that among different batches of oocytes the control oocytes expressing rat NaPi-IIa always exhibited currents three- to fivefold greater than those expressing mouse NaPi-IIb. The latter were usually in the range -20 to $-60 \mathrm{nA}$ $\left(V_{\mathrm{h}}=-50 \mathrm{~m} V, 1 \mathrm{~mm} \mathrm{P}_{\mathrm{i}}\right)$.

The steady-state $I-V$ data (Fig. $2 \mathrm{C}$ ) revealed a clear difference between the two isoforms. The NaPiIIb $I-V$ was curvilinear and for $V>-40 \mathrm{~m} V$ it flattened. This behavior indicated that voltage-independent transitions in the cotransport cycle were ratelimiting determinants of the electrogenic response for depolarizing potentials. In the hyperpolarizing region, the $I-V$ data for rat NaPi-IIa typically also showed a tendency toward rate-limiting behavior, giving an overall sigmoidal appearance, whereas mouse NaPi-IIb data exhibited a near linear relationship with $V$. Taken together with the qualitative difference in the pre-steady-state relaxations, the steady-state $I-V$ data provide clear evidence that the voltage-dependent kinetics differ between these two mammalian type II cotransporters.

Next, we quantified the steady-state behavior of $\mathrm{NaPi}-\mathrm{IIb}$ in response to varying the driven $\left(\mathrm{P}_{\mathrm{i}}\right)$ or driving $\left(\mathrm{Na}^{+}\right)$substrates. Figure 3A shows a set of $I-V$ data obtained from a representative oocyte in response to externally applied $\mathrm{P}_{\mathrm{i}}$ in the range $0.001-1 \mathrm{~mm}$ in the presence of $100 \mathrm{mM} \mathrm{Na}^{+}$(ND100 superfusate). We observed clear evidence of saturation for $\mathrm{P}_{\mathrm{i}}>0.1 \mathrm{~mm}$. For these data sets, we limited
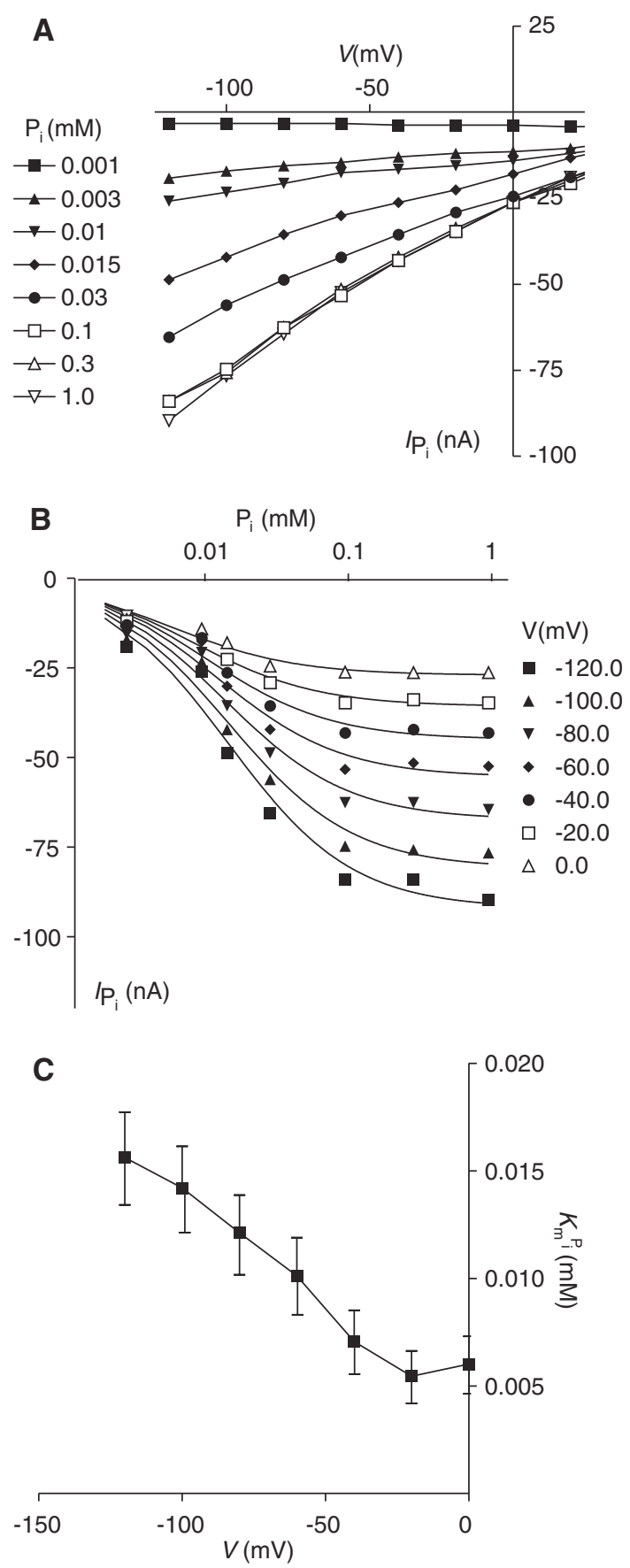

Fig. 3. $\mathrm{P}_{\mathrm{i}}$ dose response for mouse $\mathrm{NaPi}-\mathrm{IIb}$ in the presence of $100 \mathrm{~mm} \mathrm{Na}^{+}$. (A) $I-V$ data for a representative NaPi-IIb-expressing cell obtained by subtracting records in ND100 from corresponding records in $\mathrm{ND} 100+\mathrm{P}_{\mathrm{i}}$, where $\mathrm{P}_{\mathrm{i}}$ is the concentration indicated. Data points are joined for visualization. $(B)$ Data in $(A)$ replotted as a $\mathrm{P}_{\mathrm{i}}$ dose response for test potentials in the range $-120 \leq V \leq$ $0 \mathrm{~m} V$ and fit with equation $1\left(n_{\mathrm{H}}=1\right)$. (C) Apparent affinity constant for $\mathrm{P}_{\mathrm{i}}\left(K_{\mathrm{m}} \mathrm{P}_{\mathrm{i}}\right)$ plotted as a function of test potential $(n=6) . \mathrm{P}_{\mathrm{i}}$ dose responses for individual oocytes were fit with equation 1 and the reported $\left(K_{\mathrm{m}}{ }^{\mathrm{P}_{\mathrm{i}}}\right)$ values pooled.

the range of data analysis $-120 \mathrm{mV} \leq V \leq 0 \mathrm{mV}$ where we were confident that contamination from endogenous currents was negligible. When these data 
were replotted in the form of a dose response (Fig. 3B), they were well described by fitting with the Hill equation (equation 1), which yielded Hill coefficients in the range 0.9-1.1. This established that the $P_{i}$ dependence followed a Michaelian response that is characteristic of electrogenic type II $\mathrm{Na}^{+} / \mathrm{P}_{\mathrm{i}}$ cotransporters (Forster et al., 1997, 1998; Nalbant et al., 1999, Virkki et al., 2005b). Figure 3C shows the voltage dependence of the apparent affinity constant for $\mathrm{P}_{\mathrm{i}}\left(K_{\mathrm{m}} \mathrm{P}_{\mathrm{i}}\right)$ obtained from similar fits using equation 1 with the Hill coefficient $n_{\mathrm{H}}$ constrained to unity. There was an obvious inverse voltage dependence of $K_{\mathrm{m}}^{\mathrm{P}_{\mathrm{m}}}$, which indicated that the apparent affinity for $\mathrm{P}_{\mathrm{i}}$ decreased with membrane hyperpolarization. This behavior is the opposite of that reported for rat renal NaPi-IIa (Forster et al., 1998) but similar to that of human renal NaPi-IIa (Virkki et al., 2005b) and flounder NaPi-IIb (Virkki et al., 2006) and zebrafish NaPi-IIb2 (Graham et al., 2003), determined under the same experimental conditions.

Figure 4 documents the steady-state behavior of a representative oocyte expressing $\mathrm{NaPi}-\mathrm{IIb}$ when we varied the external $\mathrm{Na}^{+}$concentration in response to application of $1 \mathrm{~mm} \mathrm{P}_{\mathrm{i}}$ that was well above the apparent $K_{\mathrm{m}}{ }^{\mathrm{P}_{\mathrm{i}}}$ (Fig. 3C). Like the $\mathrm{P}_{\mathrm{i}}$-activation data, we observed saturation for $\mathrm{Na}^{+}>50 \mathrm{~mm}$ over a wide range of test potentials (Fig. 4A). When we replotted these data in the form of an $\mathrm{Na}^{+}$dose response, they were well fit using the Hill equation (Fig. 4B); and when plotted on a linear abscissa, the fitted curves showed an obvious inflexion at low $\mathrm{Na}^{+}$, which was indicative of a cooperative $\mathrm{Na}^{+}$interaction involving $>1 \mathrm{Na}^{+}$ion. Figure $4 \mathrm{C}$ summarizes the voltage dependence of the apparent $\mathrm{Na}^{+}$affinity $\left(K_{\mathrm{m}}{ }^{\mathrm{Na}}\right)$ and the Hill coefficient $\left(n_{\mathrm{H}}\right)$ reported by the fitting algorithm for fits to pooled data $(n=4)$. In contrast to $K_{\mathrm{m}}{ }^{\mathrm{P}_{\mathrm{i}}}, K_{\mathrm{m}}{ }^{\mathrm{Na}}$ decreased with hyperpolarizing potentials, which indicated that the apparent $\mathrm{Na}^{+}$ affinity increased with membrane hyperpolarization. This behavior agrees with that previously reported for rat renal NaPi-IIa (Forster et al., 1998) and human renal NaPi-IIa (Virkki et al., 2005b) as well as flounder NaPi-IIb (Virkki et al., 2006). The Hill coefficient was relatively insensitive to membrane voltage, with the error increasing as $V$ approached $0 \mathrm{~m} V$ due to the fit uncertainty, because at these potentials the $\mathrm{NaPi}$-IIb-associated currents were small.

\section{Pre-Steady-State kinetics of NAPI-IIb}

As depicted in Figure 2A, voltage steps induced pre-steady-state relaxations in the absence of $\mathrm{P}_{\mathrm{i}}$. We were unable to detect charge movement in the presence of saturating $\mathrm{P}_{\mathrm{i}}(1 \mathrm{~mm})$, in addition to that associated with the normal oocyte capacitive transient (data not shown). The charge movements corresponding to these relaxations reflect the
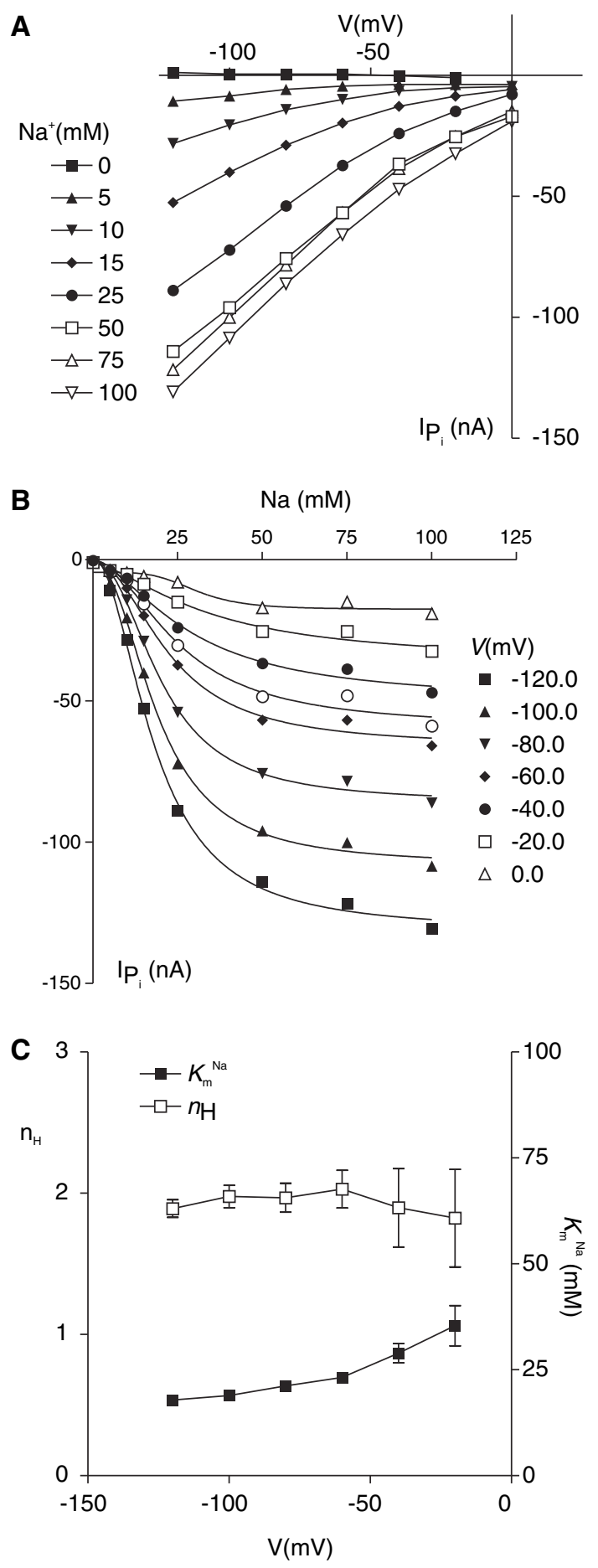

Fig. 4. $\mathrm{Na}^{+}$dose response for mouse $\mathrm{NaPi}-\mathrm{II} b$ in response to $1 \mathrm{~mm}$ $\mathrm{P}_{\mathrm{i}}$. (A) $I-V$ data for a representative NaPi-lib-expressing cell obtained by subtracting records in NDX from corresponding records in NDX $+1 \mathrm{~mm} \mathrm{P}_{\mathrm{i}}$, where $X$ is the $\mathrm{Na}^{+}$concentration indicated. Data points joined for visualization. $(B)$ Data in $(A)$ replotted as $\mathrm{Na}^{+}$dose response for the test potentials in the range$120 \leq V \leq 0 \mathrm{~m} V$ and fit with equation 1. (C) Apparent affinity constant for $\mathrm{Na}^{+}\left(K_{\mathrm{m}}^{\mathrm{Na}}\right)$ and Hill coefficient $\left(n_{\mathrm{H}}\right)$ plotted as a function of test potential $(n=4)$. $\mathrm{Na}^{+}$dose responses for individual oocytes were fit with equation 1 and the reported $K_{\mathrm{m}}{ }^{\mathrm{Na}}$ values pooled. 
nonlinear displacement of mobile charges in response to changes in membrane potential and represent a hallmark of electrogenic type II $\mathrm{Na}^{+} / \mathrm{P}_{i}$ cotransporter kinetics. Figure 5A depicts the presteady-state relaxations recorded from a representative cell for superfusion in ND0 $\left(0 \mathrm{~mm} \mathrm{Na}^{+}\right)$and ND100 (100 $\left.\mathrm{mM} \mathrm{Na}^{+}\right)$in response to voltage pulses from $V_{\mathrm{h}}=-60 \mathrm{~m} V$ to values in the range -160 to $+80 \mathrm{~m} V$. The steady-state currents associated with endogenous and NaPi-IIb-related activity were eliminated for both the ON (starting from $V_{\mathrm{h}}$ ) and OFF (returning to $V_{\mathrm{h}}$ ) voltage transitions. In the absence of external $\mathrm{Na}^{+}$(ND0), we also resolved relaxations, which appeared to be symmetrically distributed around $V_{\mathrm{h}}$ (Fig. 5A, upper traces). The addition of $100 \mathrm{~mm} \mathrm{Na}^{+}$to the external medium (ND100) changed this charge distribution dramatically (Fig. 5A, lower traces): more charge was induced for depolarizing steps and the relaxations appeared slower. To examine these effects in more detail, we quantified the charge by fitting the relaxations with a single exponential function (Fig. 5A, red traces). Figure 5B shows the voltage dependence of the time constant reported by the fit for the two superfusion conditions. These data confirmed that the relaxation rate $\left(\tau_{\mathrm{ON}}\right)$ was significantly slower in ND100 than in ND0 and that $\mathrm{Na}^{+}$ affected the voltage dependence of the relaxations by shifting the maximum of the $\tau_{\mathrm{ON}^{-}}-\mathrm{V}$ data. The greater uncertainty in $\tau_{\mathrm{ON}}$ for potentials close to $V_{\mathrm{h}}$ was attributable to the poorer signal-to-noise ratio for smaller voltage jumps.

We quantified the amount of translocated charge by numerical integration of the fitted component, extrapolated to the voltage step onset. We neglected the small overestimate of charge due to the limited rise time of the voltage clamp. We first tested for charge balance between the ON and OFF relaxations: as shown in Figure 5C for the same cell as in A, there was an obvious linear correlation between the $\mathrm{ON}$ and OFF charge over the range of test potentials used for both superfusion conditions (slope for ND100 $-1.16 \pm 0.02$, slope for ND0 $-1.04 \pm 0.05$ ). We would expect a charge balance for a memoryless process involving the translocation of a fixed number of charges, and this was an indirect indication that the fitting procedure had extracted charge from the same physical process in the ON and OFF transitions under two superfusion conditions.

The voltage dependence of the ON charge $\left(Q_{\mathrm{ON}}\right)$ for different $\mathrm{Na}^{+}$concentrations is depicted in Figure 5D. These data were normalized to the maximum charge $\left(Q_{\max }\right)$ predicted from fitting a Boltzmann function (equation 2) to data from individual cells $(n=4)$ and offset to superimpose the $Q-V$ curves at the depolarizing limit. This procedure revealed that the charge distribution was shifted toward hyperpolarizing potentials as we reduced external
$\mathrm{Na}^{+}$. This behavior was also consistent with the altered voltage dependence of $\tau_{\mathrm{ON}}$ (Fig. 5B). We quantified this shift in terms of the midpoint potential $\left(V_{0.5}\right)$ of the distribution (Fig. 5E), which, when plotted on a logarithmic scale, showed a linear relationship between $V_{0.5}$ and $\log$ [Na]. A linear regression fit to these data for $[\mathrm{Na}] \geq 10 \mathrm{~mm}$ reported a slope of $65 \pm 8 \mathrm{~m} V / \log$ [Na] (Fig. 5E, inset). The maximum translocatable charge reported by the fitting algorithm $\left(Q_{\max }\right)$ for the pooled data, normalized to $Q_{\max }$ at $100 \mathrm{~mm} \mathrm{Na}{ }^{+}$, showed a small decrease with diminishing $\mathrm{Na}^{+}$(Fig. 5F), and for superfusion in ND0 the maximum moveable charge was approximately $50 \%$ of that at ND100. The apparent valency $(z)$ did not show any systematic dependence on $\mathrm{Na}^{+}$, given the uncertainties in the fitting procedure.

\section{The Effect of pH on Steady-State and Pre-Steady- STATE Kinetics}

We have previously documented, by means of ${ }^{32} \mathrm{P}_{\mathrm{i}}$ uptake assays, that mouse intestinal $\mathrm{NaPi}-\mathrm{IIb}$ displays less $\mathrm{pH}$ dependence than mouse renal NaPiIIa (Hilfiker et al., 1998; de la Horra et al., 2000). To investigate this behavior in more detail under voltage-clamp conditions, we recorded steady-state and pre-steady-state currents with varying external $\mathrm{pH}$ and constant total $\mathrm{P}_{\mathrm{i}}(1 \mathrm{~mm})$. Figure 6A shows pooled $I-V$ data for NaPi-IIb-expressing oocytes at four $\mathrm{pH}$ values $(n=10)$. For each cell, we first normalized the $I_{\mathrm{P}_{\mathrm{i}}}$ data at $-100 \mathrm{~m} V, \mathrm{pH} 7.4$, before pooling. For a decrease in $\mathrm{pH}$ from 7.4 to 6.2 , there was $\sim 30 \%$ reduction in $I_{\mathrm{P}_{\mathrm{i}}}(V=-60 \mathrm{~m} V)$ compared to $>50 \%$ reported for NaPi-IIa (Forster et al., 1998; Forster, Biber \& Murer, 2000; Virkki et al., 2005b). Moreover, there appeared to be little difference between the response at $\mathrm{pH} 6.2$ and 5.6. The curvilinear steady-state voltage dependence of $I_{\mathrm{P}_{\mathrm{i}}}$ was maintained for all $\mathrm{pH}$ values, and the effects were reversible (data not shown).

As illustrated in Figure 6B for a representative oocyte, the decrease in cotransport activity was paralleled by a concomitant decrease in pre-steadystate charge movement. The ON transition time constants $\left(\tau_{\mathrm{ON}}\right)$ obtained by fitting pre-steady-state relaxations with a single exponential were found not to alter significantly for a $\mathrm{pH}$ decrease from 7.4 to 6.2 (Fig. 6C). There was a larger uncertainty in the fit for hyperpolarizing voltage steps at $\mathrm{pH} 7.4$ and over the whole voltage range for $\mathrm{pH} 6.2$ because of the poorer signal-to-noise ratio. Quantification of the pre-steady-state charge movements by fitting the $Q-V$ data with the Boltzmann function (equation 2) indicated that acidification to $\mathrm{pH}$ 6.2 resulted in a progressive reduction in $Q_{\max }$, as suggested from the original data. Consistent with the steady-state data, this effect was reversible (data 
A
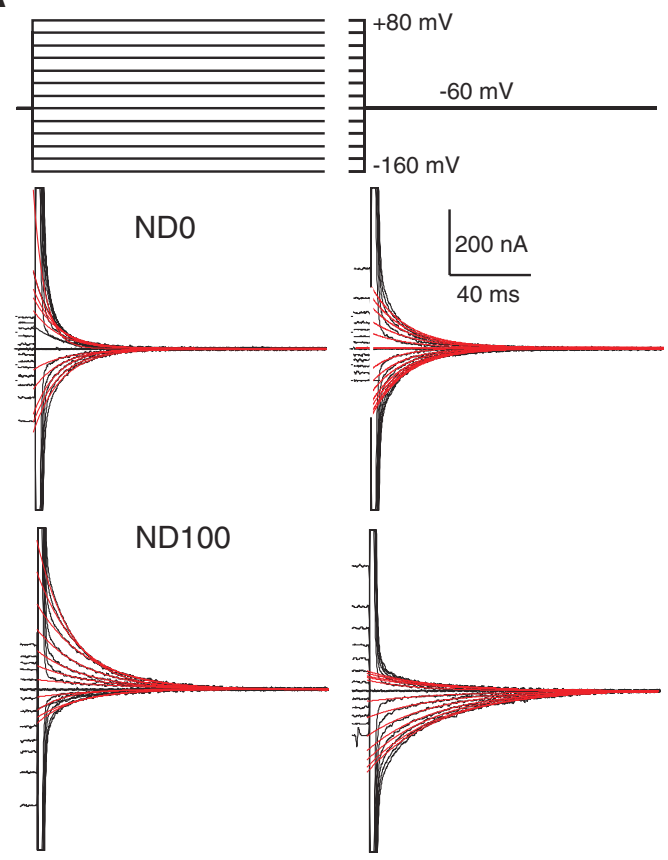
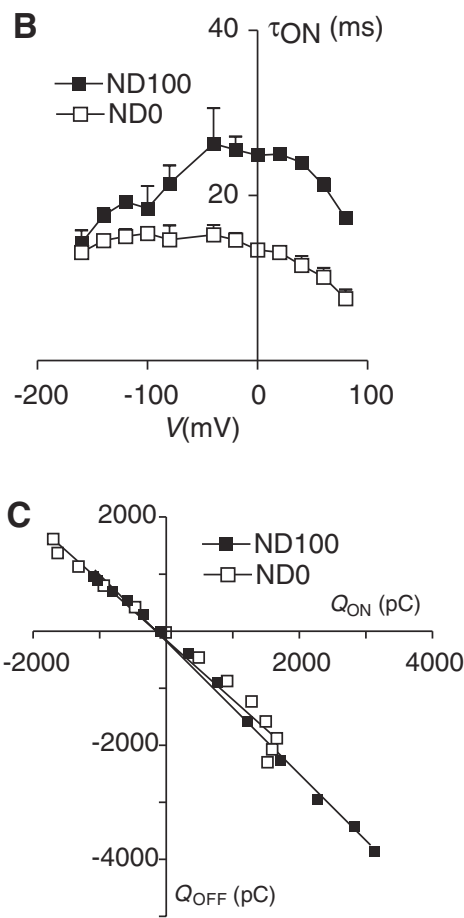

D

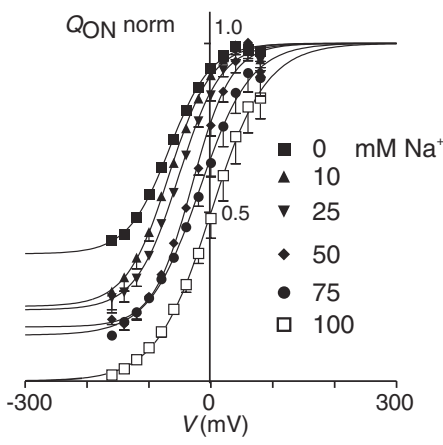

$\mathbf{F}$

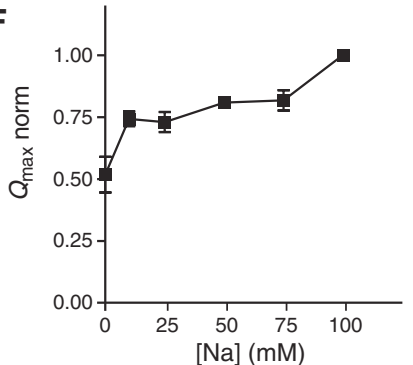

E
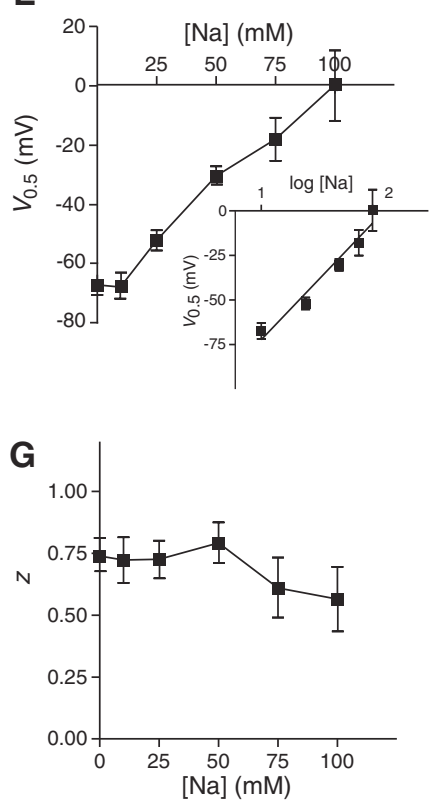

Fig. 5. Pre-steady-state charge movements and external $\mathrm{Na}^{+}$. (A) Pre-steady-state currents recorded from a representative oocyte expressing $\mathrm{NaPi}-\mathrm{IIb}$ to the voltage step protocol shown for superfusion in $0 \mathrm{mM} \mathrm{Na}^{+}$(ND0) and $100 \mathrm{~mm} \mathrm{Na}^{+}$(ND100). The pulse width was $150 \mathrm{~ms}$. Individual traces have been corrected for baseline shifts and are shown for the ON transition (steps from $V_{\mathrm{h}}=-60 \mathrm{~m} V$ ) to test potential (left traces) and OFF transition (from test potential to $-60 \mathrm{mV}$ ). The fitted single exponential curve that represents the main relaxation is shown superimposed (red traces). (B) Time constant associated with main relaxation following the ON transition $\left(\tau_{\mathrm{ONN}}\right)$, as reported by the fitting algorithm for the two superfusion conditions $(n=4)$. (C) Charge balance is maintained for the ON and OFF charge movements for the oocyte in $(A)$. Each point represents the ON charge $\left(Q_{\mathrm{ON}}\right)$ and OFF charge $\left(Q_{\mathrm{OFF}}\right)$ for the same voltage step in the range -160 to $+80 \mathrm{~m} V$ for the two superfusion conditions. Straight lines are linear regression fits with slopes $-1.04 \pm 0.05$ (ND0) and $-1.16 \pm 0.02$ (ND100). $(D)$ Normalized $Q_{\mathrm{ON}}$ plotted as a function of voltage for different external $\mathrm{Na}^{+}$concentrations indicated. Data sets from individual cells were first fitted with equation 2 to estimate $Q_{\max }$. Data were then normalized, pooled and offset such that the fits superimposed at the depolarizing limit. $(E)$ Dependence of midpoint potential of $Q_{\mathrm{ON}}$ distribution $\left(V_{0.5}\right)$ as a function of external $\mathrm{Na}^{+}$concentration. Points are joined for visualization. Inset shows same data (omitting $0 \mathrm{~mm} \mathrm{Na}^{+}$) replotted on a $\log [\mathrm{Na}]$ scale. Straight line is a linear regression fit to data points with a slope of $-65 \mathrm{~m} V /$ decade [Na]. $(F)$ Dependence of maximum translocatable charge $Q_{\max }$ on [Na] $(n=4)$. Data for each cell were normalized to $Q_{\max }$ at $100 \mathrm{~mm} \mathrm{Na}{ }^{+}$. Points are joined for visualization. $(G)$ Dependence of apparent valency $(z)$ on $[\mathrm{Na}](n=4)$. 

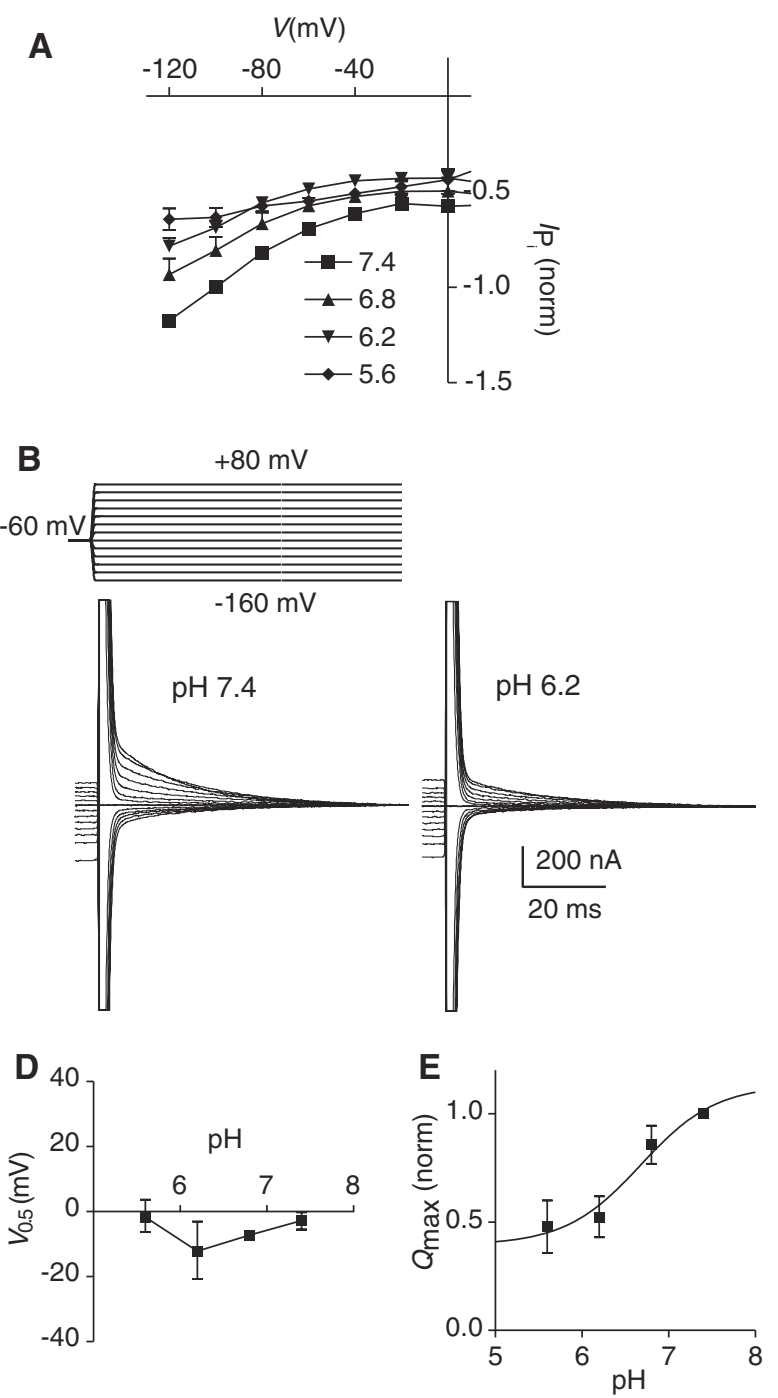

not shown). As indicated in Figure $6 \mathrm{D}$ and $\mathrm{F}$, there was no systematic shift in either $V_{0.5}$ or $z$ with increasing acidification; and as confirmed in Figure 6E, $Q_{\max }$ decreased to approximately $50 \%$ for change from $\mathrm{pH} 7.4$ to 5.6 . We fit the $Q_{\max }$ data with a one-site inhibition equation (continuous curve, Fig. 6E), which yielded an inhibition constant of $0.16 \mu \mathrm{M}$ for $\mathrm{H}^{+}$.

Finally, we performed experiments in which pre-steady-state currents were acquired in $0 \mathrm{~mm} \mathrm{Na}^{+}$ (ND0) to investigate whether the $\mathrm{pH}$ affected empty carrier kinetics, as we have previously reported for rat $\mathrm{NaPi}-\mathrm{II} a$ and flounder NaPi-IIb (Forster et al., 2000) and human NaPi-IIa (Virkki et al., 2005b). As summarized in Table 1, the fit parameters reported by a single Boltzmann fit indicated that the total charge in ND0 did not change significantly for a decrease in $\mathrm{pH}$ from 7.4 to 6.2. However, we did observe a small shift in $V_{0.5}$ potential in the depolarizing direction under the same conditions, with no change in the apparent valency, $z$, of the empty carrier.

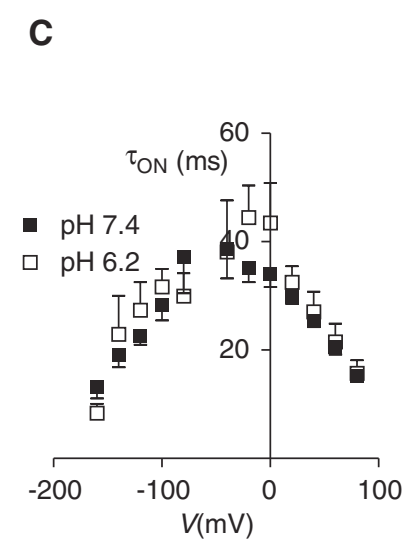

Fig. 6. Steady-state and pre-steady-state $\mathrm{pH}$ dependence of mouse NaPi-IIb. $(A)$ Normalized steady-state $I_{\mathrm{Pi}}$ as a function of membrane potential. Data were normalized to $I_{\mathrm{Pi}}$ at $-100 \mathrm{~m} V, \mathrm{pH}$ $7.4(n=10)$. Excessive contamination from endogenous activating currents, especially at low $\mathrm{pH}$ values, prevented reliable quantification of $I_{\mathrm{Pi}}$ for $V<-120$ $\mathrm{m} V$ and $V>0 \mathrm{~m} V$.

(B) ON-transition pre-steady-state relaxations recorded from a representative oocyte at $\mathrm{pH} 7.4$ (left) and pH 6.2 (right) in response to the voltage protocol shown. Records were baselinecorrected to better illustrate the reduction in charge movement. (C) Voltage dependence of relaxation time constant $\left(\tau_{\mathrm{ON}}\right)$ for pH 7.4 and 6.2. Data pooled $(n=5)$. (D) $\mathrm{pH}$ dependence of midpoint voltage $\left(V_{0.5}\right)$ reported by a Boltzmann fit (equation 2) to the $Q-V$ data $(n=4)$. $(E) \mathrm{pH}$ dependence of maximum translocatable charge $\left(Q_{\max }\right)$ reported by the Boltzmann fit $(n=4)$. The data were normalized to $Q_{\max }$ at $\mathrm{pH} 7.4$ for each cell. $(F) \mathrm{pH}$ dependence of apparent valency $(z)$ reported by the Boltzmann fit $(n=4)$.

Table 1. Summary of dependence of Boltzmann fit parameters on $\mathrm{pH}$ in the absence of external $\mathrm{Na}^{+}$(ND0)

\begin{tabular}{llll}
\hline Ph & $Q_{\max }^{*}$ & $V_{0.5}(\mathrm{~m} V)$ & $z$ \\
\hline 7.4 & $0.67 \pm 0.02$ & $-80 \pm 6$ & $0.54 \pm 0.07$ \\
6.2 & $0.61 \pm 0.05$ & $-62 \pm 6$ & $0.52 \pm 0.06$
\end{tabular}

*Normalized to $Q_{\max }$ in ND100 at $\mathrm{pH} 7.4$ and pooled $(n=5)$.

\section{Discussion}

This investigation documents the electrogenic properties of mouse intestinal NaPi-IIb cotransporter in the steady state and pre-steady state and complements other studies on mammalian (Busch et al., 1994; Hartmann et al., 1995; Forster et al., 1998; Virkki et al., 2005b) and nonmammalian (Forster et al., 1997; Nalbant et al., 1999; Graham et al., 2003) type II electrogenic $\mathrm{Na}^{+} / \mathrm{P}_{\mathrm{i}}$ cotransporters. These studies are important not only for relating the 
cotransporter's physiological role to phenomenological kinetic parameters such as apparent substrate affinities but also for information for structure-function studies. In this respect, we can use kinetic differences between related isoforms to identify functionally important regions and sites that confer specific macroscopic characteristics. As many of these characteristics are interrelated, it is important that the kinetic characterization of the transporter protein be as complete as possible and made over as wide a range of externally definable parameters as experimentally feasible.

Despite having a high degree of sequence similarity, familial relatedness (Fig. 1) and predicted topological identity, previous studies on wild-type type II $\mathrm{Na}^{+} / \mathrm{P}_{\mathrm{i}}$ cotransporters have revealed clear differences in their kinetic fingerprints between and within subtypes (Nalbant et al., 1999; Forster et al., 2000, 2002a; Werner \& Kinne, 2001; Graham et al., 2003). These arise from small changes in their primary structure, as we have found in studies on the mammalian renal $\mathrm{NaPi}-\mathrm{IIa}$, in which single point mutations were made (Lambert et al., 2001; Kohler et al., 2002; Ehnes et al., 2004; Virkki et al., 2005a). We have exploited these differences in two studies on wild-type protein function to identify structurefunction relationships for $\mathrm{pH}$ dependence and voltage dependence. In the first study, the $\mathrm{pH}$ dependences of mouse NaPi-IIa and NaPi-IIb were interconverted through substitution of the corresponding amino acids from each protein (de la Horra et al., 2000). This study was based on uptake assays because of the low expression levels; therefore, the influence of membrane potential could not be assessed. In the second study, we reported that a change of three amino acids in the predicted third transmembrane domain of the electroneutral mouse NaPi-IIc introduces electrogenic behavior with a concomitant increase in $\mathrm{Na}^{+}: \mathrm{P}_{\mathrm{i}}$ stoichiometry from $2: 1$ to $3: 1$ (Bacconi et al., 2005), while in human NaPi-IIa substitution of one of the equivalent $\mathrm{NaPi}$-IIa residues removed electrogenicity but retained $\mathrm{Na}^{+}$-dependent $\mathrm{P}_{\mathrm{i}}$ cotransport function (Virkki et al., 2005a). Indeed, because in general the measured cotransporter kinetics are thought to result from a series of molecular rearrangements between multiple conformational states, the occupancy of which depends on external factors such as substrate concentration, $\mathrm{pH}$ and membrane potential, it is not surprising that other characteristics can also be affected. For example, the minor substitutions that conferred electrogenicity to electroneutral mouse $\mathrm{NaPi}$-IIc resulted in a significantly weaker voltage dependence than wild-type NaPi-IIa and, moreover, the apparent $P_{i}$ affinity was $>10$-fold lower than for either wild-type protein (Bacconi et al., 2005).

The mouse NaPi-IIb transporter investigated here also presents a unique kinetic profile that could be exploited for future structure-function work. Table 2 summarizes its main kinetic features and compares them with those of representative members of the type II $\mathrm{Na}^{+} / \mathrm{P}_{\mathrm{i}}$ family for which complete characterizations are available that have been determined under the same experimental conditions.

\section{Steady-State Substrate InTeractions}

Mouse NaPi-IIb most probably functions with a $\mathrm{Na}^{+}: \mathrm{P}_{\mathrm{i}}$ stoichiometry of $3: 1$ like other electrogenic members of the type II $\mathrm{Na}^{+} / \mathrm{P}_{\mathrm{i}}$ cotransporter family (Forster et al., 1999; Virkki et al., 2005b). Our finding that the Hill coefficient for $\mathrm{Na}^{+}$interaction was $\sim 2$ would also support this conclusion. The apparent affinity constant for $\mathrm{Na}^{+}\left(K_{\mathrm{m}}{ }^{\mathrm{P}_{\mathrm{i}}}\right)$ lay in the same range as the other isoforms, and this parameter also decreased with membrane hyperpolarization, consistent with a voltage-dependent interaction of $\mathrm{Na}^{+}$ ions with the transporter. In contrast, the apparent affinity constant for $\mathrm{P}_{\mathrm{i}}\left(K_{\mathrm{m}}{ }^{\mathrm{P}_{\mathrm{i}}}\right)$ was approximately 10 fold lower than that of the other isoforms, including electroneutral NaPi-IIc. Such a high $\mathrm{P}_{\mathrm{i}}$ affinity might be of physiological relevance because it would ensure that mammalian $\mathrm{NaPi}-\mathrm{IIb}$ is always operating under $V_{\max }$ conditions over a wide range of $\mathrm{P}_{\mathrm{i}}$ concentrations in the gut lumen. Like the human NaPi-IIa (Virkki et al., 2005b), $K_{\mathrm{m}}{ }^{\mathrm{P}_{i}}$ increased with membrane hyperpolarization. This contrasts with rat NaPi-IIa and flounder $\mathrm{NaPi}-\mathrm{II} b$, for which we have previously reported a decreased apparent $P_{i}$ affinity with hyperpolarization (Forster et al., 1998; Virkki et al., 2006a,b). Our findings for mouse NaPi-IIb suggest that part or all of the $\mathrm{P}_{\mathrm{i}}$ interaction with the protein is transmembrane field-dependent. For human NaPi-IIa, this characteristic was simulated using an eight-state model (Fig. 7A) in which the $\mathrm{P}_{\mathrm{i}}$ binding partial reaction involved charge movement (Virkki et al., 2005b). This would imply that charge movements should also occur in the presence of $\mathrm{P}_{\mathrm{i}}$; however, for mouse $\mathrm{NaPi}$-IIb we were unable to distinguish NaPi-IIb-related nonlinear charge movements from the endogenous oocyte capacity charging component.

\section{EFFECT OF PH}

A detailed study of the effect of $\mathrm{pH}$ on intestinal $\mathrm{P}_{\mathrm{i}}$ transport using rabbit duodenal brush border membrane vesicles (BBMVs) reported increased vesicular uptake with external acidification (Danisi, Murer \& Straub, 1984). This was the opposite behavior reported for $\mathrm{P}_{\mathrm{i}}$ uptake for the renal proximal tubule BBMV preparation (Amstutz et al., 1985) and provides strong evidence that the two $\mathrm{Na}^{+}$-dependent transport systems respond differently to changes in external pH. Nevertheless, the results of BBMV uptake studies should be treated with some caution 
Table 2. Comparison of selected kinetic parameters for members of the SLC34 family

\begin{tabular}{|c|c|c|c|c|c|}
\hline & $\mathrm{NaPi}-\mathrm{IIa},{ }^{\mathrm{a}, \mathrm{b}}$ rat & NaPi-IIa, ${ }^{c}$ human & NaPi-IIb, ${ }^{\mathrm{d}}$ mouse & $\mathrm{NaPi}-\mathrm{IIb},{ }^{\mathrm{e}}$ flounder & NaPi-IIc, ${ }^{\text {f,g }}$ mouse \\
\hline Electrogenic & Yes & Yes & Yes & Yes & No \\
\hline Stoichiometry $\mathrm{Na}^{+}: \mathrm{P}_{\mathrm{i}}$ & $3: 1$ & $3: 1$ & nd & $3: 1$ & $2: 1$ \\
\hline$K_{\mathrm{m}}^{\mathrm{Pi}}$ at & & & & & 70 \\
\hline$-20 \mathrm{~m} V^{\mathrm{h}}$ & $83 \pm 10$ & $72 \pm 7$ & $6 \pm 1$ & $60 \pm 13$ & \\
\hline$-120 \mathrm{~m} V(\mu \mathrm{M})$ & $56 \pm 9$ & $120 \pm 7$ & $15 \pm 1$ & $63 \pm 11$ & \\
\hline$K_{\mathrm{m}}^{\mathrm{Na}}$ at & & & & & $48 \pm 9$ \\
\hline$-20 \mathrm{~m} V^{\mathrm{h}}$ & $56 \pm 2$ & $46 \pm 7$ & $36 \pm 5$ & $40 \pm 4$ & \\
\hline$-120 \mathrm{~m} V(\mathrm{~mm})$ & $51 \pm 4$ & $59 \pm 7$ & $18 \pm 1$ & $29 \pm 2$ & \\
\hline Cotransport and $\mathrm{pH} \downarrow$ & Strong $\downarrow$ & Strong $\downarrow$ & Weak $\downarrow$ & Strong $\downarrow$ & Strong $\downarrow$ \\
\hline$V_{0.5}(\mathrm{~m} V)$ at & & & & & na \\
\hline $100 \mathrm{~mm} \mathrm{Na}^{+}$ & $-66.3^{j}$ & $-23 \pm 4$ & $4 \pm 1$ & $10 \pm 4$ & \\
\hline $0 \mathrm{mM} \mathrm{Na}^{+}$ & $-94.5^{1}$ & $-74 \pm 6$ & $-73 \pm 8$ & $-29 \pm 4$ & \\
\hline $\begin{array}{l}\text { Slope } V_{0.5} \text { vs. } \log [\mathrm{Na}]\left(\mathrm{m} V / \text { decade } \mathrm{Na}^{+}\right) \\
z \text { at }\end{array}$ & nd & $94 \pm 6$ & $65 \pm 8$ & $113 \pm 11$ & na \\
\hline $100 \mathrm{~mm} \mathrm{Na}^{+}$ & $0.47^{\mathrm{j}}$ & $0.55 \pm 0.03^{\mathrm{i}}$ & $0.8 \pm 0.1$ & $0.6 \pm 0.03$ & na \\
\hline $0 \mathrm{~mm} \mathrm{Na}^{+}$ & $0.48^{\mathrm{j}}$ & $0.5 \pm 0.1$ & $0.8 \pm 0.1$ & $0.4 \pm 0.1$ & \\
\hline$\phi\left(\mathrm{s}^{-1}\right)$ at $-60 \mathrm{~m} V$ & $4.1 \pm 0.6^{\mathrm{d}}$ & $9 \pm 1^{\mathrm{i}}$ & $5.3 \pm 0.4$ & $13 \pm 2^{\mathrm{b}}$ & nd \\
\hline
\end{tabular}

${ }^{\text {a}}$ Forster et al., 1998.

${ }^{\mathrm{b}}$ I. C. Forster, unpublished results.

${ }^{\mathrm{c}}$ Virkki et al., 2005b.

${ }^{\mathrm{d}}$ This study.

${ }^{\mathrm{e}}$ Virkki et al., 2006 a,b.

${ }^{\text {f}}$ Segawa et al., 2002.

${ }^{\mathrm{g}}$ Bacconi et al., 2005.

${ }^{\mathrm{h}} K_{\mathrm{m}}{ }^{\mathrm{P}_{\mathrm{i}}}$ measured at $100 \mathrm{mM} \mathrm{Na}^{+}, K_{\mathrm{m}}{ }^{\mathrm{Na}}$ at $1 \mathrm{mM} \mathrm{P}$.

${ }^{\mathrm{i}} \mathrm{L}$. V. Virkki, unpublished data.

${ }^{\mathrm{j}}$ Forster et al., 2002b.

na, not applicable; nd, not determined.

because the protein mediating the transport is not identified and there is less control of membrane potential and leak pathways compared to oocyte electrophysiology studies.

In addition to reducing the availability of divalent $P_{i}$, the preferred species for type II cotransporters (Forster et al., 1999; Bacconi et al., 2005; Virkki et al., 2005b), protons, can also have multiple effects on the partial reactions of the cotransport cycle. Detailed kinetic studies on the effect of external protons on the voltage-dependent kinetics of rat NaPi-IIa (Forster et al., 2000), flounder NaPi-IIb (Forster et al., 2000) and human NaPi-IIa (Virkki et al., 2005b) have attempted to identify these protonsensitive partial reactions. Interestingly, the conclusions drawn from these studies indicate that the specific reaction steps are isoform-specific, whereas certain properties are shared among isoforms from different NaPi-II subgroups. For example, in rat $\mathrm{NaPi}-\mathrm{II} a$ and flounder NaPi-IIb it was concluded that protons interact with the empty carrier (8-1, Fig. 7A) and the last $\mathrm{Na}^{+}$binding reaction (3-4, Fig. 7A) (Forster et al., 2000). Pre-steady-state current analysis showed a depolarizing shift in the midpoint potential $\left(V_{0.5}\right)$ in $100 \mathrm{mM} \mathrm{Na}^{+}$and $0 \mathrm{mM} \mathrm{Na}^{+}$with unchanged $Q_{\max }$ for both superfusion conditions with decreasing $\mathrm{pH}$. These authors attributed the reduced voltage dependence of the steady-state $I_{\mathrm{P}_{\mathrm{i}}}$ with decreasing $\mathrm{pH}$ to modulation of the rate constants assigned to the empty carrier reorientation, while a competition of protons with the last (electroneutral) $\mathrm{Na}^{+}$binding reaction was proposed to account for a reduced transport rate, independent of membrane potential. A more recent study on human NaPi-IIa (Virkki et al., 2005b) also documented a shift in $V_{0.5}$ in the depolarizing direction with decreasing $\mathrm{pH}$ but with concomitant suppression of $Q_{\max }$. As the effect of protons on the empty carrier appeared less significant compared with rat $\mathrm{NaPi}-\mathrm{II} a$ and flounder $\mathrm{NaPi}-\mathrm{IIb}$, these authors proposed that protons interact principally with partial reaction $1-2$.

Several studies have addressed the effect of protons on mammalian $\mathrm{NaPi}-\mathrm{II} b$. In the original report (Hilfiker et al., 1998), ${ }^{32} \mathrm{P}_{\mathrm{i}}$ uptake by mouse $\mathrm{NaPi}-\mathrm{IIb}$ expressed in Xenopus oocytes documented a slight increase as the external $\mathrm{pH}$ was reduced from 8.0 to 6.0 , and qualitatively similar results were reported more recently for human NaPi-IIb (Xu et al., 2002). Moreover, the same findings have been reported when the mammalian isoforms were expressed in cell lines (Xu et al., 2002; Radanovic et al., 2003) and an approximately sevenfold increase in electrogenic activity was reported for human $\mathrm{NaPi}-\mathrm{IIb}$ expressed in oocytes (Feild et al., 1999). Taken together, 
A

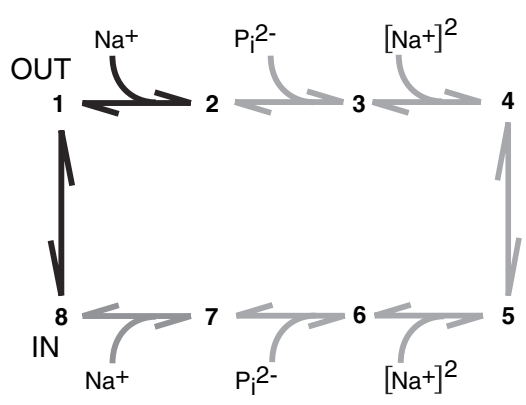

C

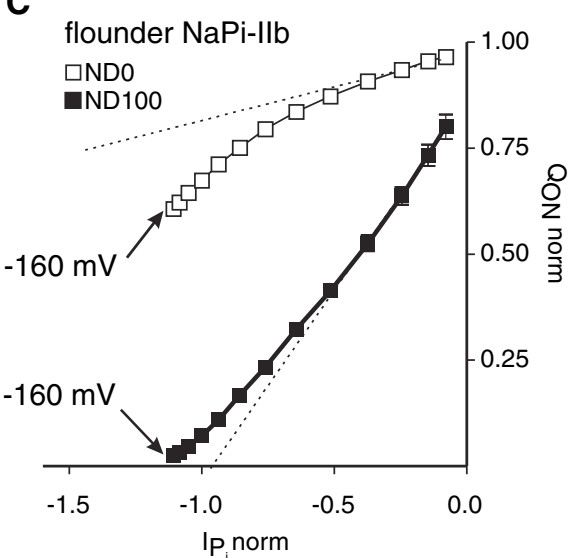

B

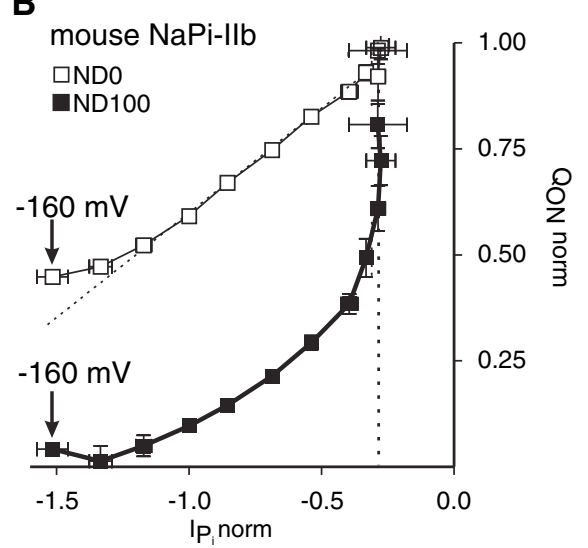

D

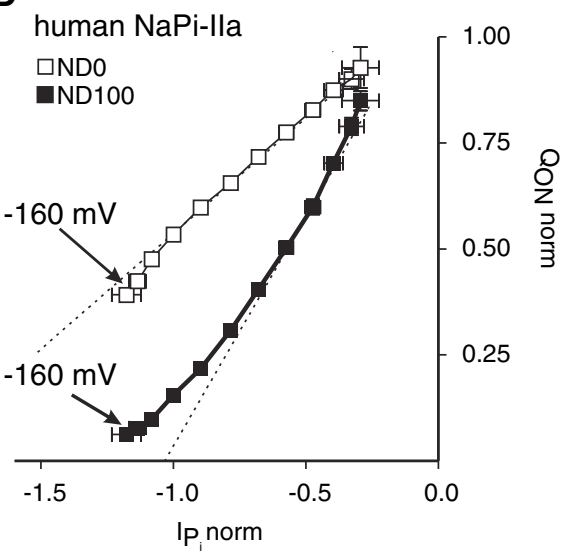

Fig. 7. (A) Kinetic scheme for type II electrogenic $\mathrm{Na}^{+} / \mathrm{P}_{\mathrm{i}}$ cotransporters. The cotransport cycle comprises sequential transitions between at least eight conformationally distinct states. Membrane hyperpolarization in the absence of external $\mathrm{Na}^{+}$will favor the empty carrier occupying state 1 because of its (assumed) intrinsic negative charge. This increases the probability of a single $\mathrm{Na}^{+}$ion occupying its binding site (state 2), which in turn facilitates $P_{i}$ binding, followed by the binding of two more $\mathrm{Na}^{+}$ions to form the electrically neutral fully loaded carrier (state 4). A voltage-independent conformational change (transition 4-5) translocates the substrates to the inside. Substrates are released sequentially, leaving the negatively charged empty carrier in an energetically unfavorable conformation (state 8) with a hyperpolarizing membrane potential so that the system returns to state 1 , thereby completing a cycle. Two partial reactions $(8-1,1-2)$ have been postulated from previous studies to involve charge movement and therefore contribute to the overall voltage dependence. $(B-D) Q-I$ parametric plots for three members of the SLC34 family: mouse NaPiIIb $(B)$, flounder NaPi-IIb $(C)$ and human NaPi-IIa $(D)$. Each plot shows the normalized pre-steady-state charge $\left(Q_{\mathrm{ON}}\right.$ norm) in the presence (ND100) and absence (ND0) of external Na ${ }^{+}$plotted against the corresponding normalized $\mathrm{P}_{\mathrm{i}}$-induced current $\left(I_{\mathrm{Pi}}\right.$ norm $)$ for the same voltage in the range -160 to $+80 \mathrm{~m} V$. Data points are joined for visualization only. Dotted lines, drawn by eye, show asymptotic behavior at depolarizing potentials. Data for mouse NaPi-IIb were obtained from this study $(n=4)$. Data for flounder NaPi-IIb were obtained from Virkki et al. (2006 a,b) and unpublished experiments by I. C. Forster $(n=7)$. Data for human NaPi-IIa were obtained from unpublished experiments by L. V. Virkki $(n=7)$. For each cell, the $I_{\mathrm{Pi}}$ data were normalized to the $\mathrm{P}_{\mathrm{i}}$-induced current $\left(1 \mathrm{~mm} \mathrm{P}_{\mathrm{i}}, \mathrm{ND} 100\right)$ at $-100 \mathrm{mV}$. $Q_{\mathrm{ON}}$ norm data were obtained by normalizing the raw data to predicted $Q_{\max }$ for a single Boltzmann fit and offset to the depolarizing limit.

this behavior of mammalian NaPi-IIb contrasts starkly with the typical $50 \%$ reduction in activity documented for renal NaPi-IIa isoforms (e.g., Forster et al., 2000; Virkki et al., 2005b) as well as flounder NaPi-IIb (Forster et al., 1997, 2000) and zebrafish NaPi-IIbl (Nalbant et al., 1999).

In the present study, mouse NaPi-IIb under voltage-clamp conditions showed $\sim 30 \%$ reduction in cotransport activity for a decrease in external $\mathrm{pH}$ from 7.4 to 5.6 . The reduced activity would only be partly due to the availability of divalent $\mathrm{P}_{\mathrm{i}}$ because even at $\mathrm{pH} 5.6$, with $1 \mathrm{~mm}$ total $\mathrm{P}_{\mathrm{i}}$, $\mathrm{HPO}_{4}{ }^{2-}=\sim 60 \mu \mathrm{M}$, which is well above the esti- mated $K_{\mathrm{m}}{ }^{{ }^{\mathrm{i}}}$ for mouse NaPi-IIb (Table 2). That this decrease in activity does not accord with uptake studies on the same isoform can be explained by the lack of membrane voltage control: i.e., uptake of $P_{i}$ results in depolarization of the oocyte membrane and a concomitant reduction in transport rate. Moreover, changing the external $\mathrm{pH}$ may change the membrane potential or the membrane resistance by affecting, e.g., ion channel activities and thus change the driving force for $P_{i}$ uptake. In our study, the most significant alteration in mouse $\mathrm{NaPi}$-IIb kinetics and the observation that provides direct evidence of the interaction of protons with mouse NaPi-IIb was the 
reduction in $Q_{\max }$. Significantly, this was not accompanied by any systematic change to either $z$ or $V_{0.5}$ derived from the Boltzmann fitting, which contrasts with the behavior of rat NaPi-IIa and flounder $\mathrm{NaPi}-\mathrm{IIb}$ (Forster et al., 2000) as discussed above.

\section{Turnover AND Expression LeVElS}

We found that oocytes expressing mouse NaPi-IIb generally exhibited smaller $\mathrm{P}_{\mathrm{i}}$-induced currents compared with rat NaPi-IIa-expressing oocytes under the same experimental conditions. These assays were performed with $1 \mathrm{~mm} \mathrm{P}_{\mathrm{i}}$ and $100 \mathrm{~mm} \mathrm{Na}{ }^{+}$, which are concentrations far in excess of the estimated $K_{\mathrm{m}} \mathrm{P}_{\mathrm{i}}$ and $K_{\mathrm{m}}{ }^{\mathrm{Na}}$, respectively, so that a lack of substrate saturation could not account for the smaller electrogenic activity of mouse NaPi-IIb. On the other hand, as depicted in Figure 2C, this difference could be a direct consequence of the curvilinear, as opposed to sigmoidal, form of the steady-state $I$ - $V$ data over the voltage range studied. However, such a comparison does not take account of differences in expression levels. To address this issue on a quantitative basis, we compared the transporter turnover rates, determined using equation 5, for different isoforms (Table 1) at $-60 \mathrm{~m} V$. Mouse NaPi-IIb shows a comparable turnover rate to the rat renal NaPi-IIa, which would suggest that the smaller, $I_{P_{i}}$ which we routinely observed, resulted from lower membrane expression of mouse $\mathrm{NaPi}-\mathrm{IIb}$. It should be noted that turnover rates determined in the above manner may be an underestimation because $z$ derived from the Boltzmann fit assumes a lumped charge movement occurring in a single step (Zampighi et al., 1995). This would not be the case, for example, if more than one charged entity moved independently through the membrane field during the conformational changes that occur with $\mathrm{Na}^{+}$interaction. Interestingly, an alternative estimate of turnover rate can be obtained from the relaxation time constants of the pre-steady-state data (Fig. 5B). Based on these data, $-60 \mathrm{mV}$, a higher turnover rate of $\sim 40 \mathrm{~s}^{-1}$ for mouse NaPi-IIb is predicted and, for the $\mathrm{NaPi}-\mathrm{II} a$ renal isoforms and flounder $\mathrm{NaPi}-\mathrm{IIb}$, which show respectively two- and fourfold faster relaxations (Forster et al., 1997, 1998), even higher turnover rates would be expected. However, this interpretation relies on a kinetic parameter obtained in the absence of $\mathrm{P}_{\mathrm{i}}$. Moreover, it assumes there are no other rate-limiting transitions in the overall cotransport cycle, which simulation studies on the type IIa isoforms suggest is most likely not the case (Forster et al., 1998; Virkki et al., 2005b).

\section{Pre-Steady-State Currents and Voltage DePENDENCE}

The steady-state voltage dependence of mouse $\mathrm{NaPi}$-IIb differs markedly from other type II iso- forms with rate-limiting behavior for depolarizing potentials and a near linear dependence on $V$ in the hyperpolarizing direction. All mammalian type IIa isoforms (Forster et al., 1998; Virkki et al., 2005b) as well as several nonmammalian type IIb isoforms (Forster et al., 1997; Graham et al., 2003) show clear evidence of rate-limiting behavior of $I_{\mathrm{P}_{\mathrm{i}}}$ for potentials below $-120 \mathrm{~m} V$. This voltage dependence is conferred to the cotransport process by partial reactions in the transport cycle that involve charge movement within the transmembrane electric field. These charge movements are manifest as pre-steady-state current relaxations. The simplest scheme that currently accounts for the experimentally observed pre-steadystate and steady-state currents of type II $\mathrm{Na}^{+} / \mathbf{P}_{\mathrm{i}}$ cotransporters incorporates at least two such partial reactions, as depicted in Figure 7A: the empty carrier (8-1) and interaction/binding of a single $\mathrm{Na}^{+}$ion (1-2) that precedes the binding of $\mathrm{P}_{\mathrm{i}}$ (Forster et al., 1998, Virkki et al., 2005b). ${ }^{2}$ Our pre-steady-state characterization was based on fitting the $Q-V$ data with a single Boltzmann function. This represents a gross simplification because at least two Boltzmann functions must be present according to our model. It follows that fit parameters such as $z$ and $V_{0.5}$ represent effective values. Attempts have been made to fit multiple Boltzmann functions to pre-steady-state data from the sodium-glucose cotransporter (SGLT1) (Krofchick, Huntley \& Silverman, 2004). In the present study, the signal-to-noise ratio of our data and contamination by activating currents at extreme potentials prevented us from attempting multiple Boltzmann fitting. The dependence of the $Q-V$ midpoint voltage $\left(V_{0.5}\right)$ on external $\mathrm{Na}^{+}$provides strong evidence of a field-driven $\mathrm{Na}^{+}$interaction, as has been described for a number of cation-driven cotransporters (e.g., Mager et al., 1993; Wadiche et al., 1995; Boorer et al., 1996; Bossi et al., 1999). According to this model, the slope of $V_{0.5} v s . \log [\mathrm{Na}]$ indicates the apparent depth of the hypothetical $\mathrm{Na}^{+}$ binding site within the transmembrane field (e.g., Mager, Cao \& Lester, 1998). As shown in Table 2, this slope varies among three of the NaPi-II isoforms, and it would be tempting to conclude that a change in $\mathrm{Na}^{+}$binding well depth distinguishes them from one another. However, we can show using simulations that the well depth predicted from a single Boltzmann fit to $Q-V$ data generated by the three-state model does not correspond to this model parameter (I. C. Forster, unpublished data). As expected, this finding reflects the limitations of the single Boltzmann

\footnotetext{
${ }^{2}$ For rat NaPi-IIa and flounder NaPi-IIb isoforms, a fast component of charge movement has also been detected in the absence of $\mathrm{Na}^{+}$, leading to the proposal of an intermediate state for the empty carrier (Forster et al., 2000); however, for mouse NaPi-IIb, we were unable to detect such a component.
} 
approximation. Nevertheless, the comparison of parameters $z$ and $V_{0.5}$ presented in Table 2 indicates that there are significant differences between isoforms that might be used as kinetic indices for comparing transporters, without invoking a mechanistic interpretation. In $0 \mathrm{mM} \mathrm{Na}^{+}$, the single Boltzmann fit parameters also show variation between isoforms. In particular, the estimated $z$ for mouse NaPi-IIb was significantly larger than that for the other isoforms, which would suggest that the empty carrier kinetics are an important determinant of cotransport electrogenics.

Given the limitations of the interpretation of the pre-steady-state data based on a single Boltzmann fit, we sought to identify the relative contribution of the two partial reactions to the cotransport voltage dependence in a model-independent manner. This was done by means of a parametric plot, where total charge movement $(Q)$ acquired in 0 or $100 \mathrm{~mm} \mathrm{Na}^{+}$ was plotted against the $\mathrm{P}_{\mathrm{i}}$-induced steady-state current $\left(I_{\mathrm{P}_{\mathrm{i}}}\right)$ for each voltage. The charge, normalized to the depolarizing limit, can be taken as a measure of the distribution of transporters between states 8 and 1 for $\operatorname{ND} 0\left(Q^{0}\right.$, corresponding to the empty carrier transition) and states 8,1 and 2 for $\operatorname{ND} 100\left(Q^{100}\right.$, corresponding to the empty carrier transition plus $\mathrm{Na}^{+}$binding) as a function of membrane potential. In this way, we could compare the voltage dependence of charge movement between states 1 and 8 or between states 8,1 and 2 with the cotransport voltage dependence (states 1-8, i.e., the full transport cycle).

Figure 7B-D shows parametric $Q-I$ plots for mouse NaPi-IIb, flounder NaPi-IIb (I. C. Forster and L. V. Virkki, unpublished data; L. V. Virkki, H. Murer \& I. C. Forster, 2006a,b) and human NaPi-IIa (Virkki et al., 2005b). For mouse NaPi-IIb (Fig. 7B) and human NaPi-IIa (Fig. 7D) there was an obvious linear relationship between $Q^{0}$ with $I_{\mathrm{P}_{\mathrm{i}}}$ over a wide potential range $(-120<V<0 \mathrm{~m} V)$. For $V>0 \mathrm{~m} V$, where $Q^{0}$ approaches saturation for mouse NaPi-IIb (Fig. 5D), the occupancy of state 8 would be high, and this also corresponds to rate-limiting behavior of $I_{\mathrm{P}_{\mathrm{i}}}$ for depolarizing potentials. The linear correlation between $I_{\mathrm{P}_{\mathrm{i}}}$ and $Q^{0}$ suggested that, for mouse $\mathrm{NaPi}-\mathrm{IIb}$ and human $\mathrm{NaPi}$-IIa, the progressive shift in occupancy of the empty carrier from state 8 to state 1 with hyperpolarizing $V$ is the main determinant of their cotransport voltage dependence and is a rate-determining transition in the overall cotransport cycle. There was no obvious linear correlation between $I_{\mathrm{P}_{\mathrm{i}}}$ and $Q^{100}$ for any of the isoforms examined, which suggested that transition $1-2$ is not a rate-determining reaction for the full cotransport cycle.

This work was financially supported by grants awarded to J. B. and H. M. from the Swiss National Science Foundation and to H. M. from the Gebert Rüf Foundation (www.grstiftung.ch). We thank Gerti Stange for expert technical assistance.

\section{References}

Amstutz, M., Mohrmann, M., Gmaj, P., Murer, H. 1985. Effect of $\mathrm{pH}$ on phosphate transport in rat renal brush border membrane vesicles. Am. J. Physiol. 248:F705-F710

Bacconi, A., Virkki, L.V., Biber, J., Murer, H., Forster, I.C. 2005. Renouncing electrogenicity is not free of charge: Switching on electrogenicity in a $\mathrm{Na}^{+}$-coupled phosphate cotransporter. Proc. Natl. Acad. Sci. USA 102:12606-12611

Beck, L., Karaplis, A.C., Amizuka, N., Hewson, A.S., Ozawa, H., Tenenhouse, H.S. 1998. Targeted inactivation of Npt2 in mice leads to severe renal phosphate wasting, hypercalciuria, and skeletal abnormalities. Proc. Natl. Acad. Sci. USA 95:5372-5377

Boorer, K.J., Loo, D.D., Frommer, W.B., Wright, E.M. 1996. Transport mechanism of the cloned potato $\mathrm{H}^{+}$/sucrose cotransporter StSUT1. J. Biol. Chem. 271:25139-25144

Bossi, E., Centinaio, E., Castagna, M., Giovannardi, S., Vincenti, S., Sacchi, V.F., Peres, A. 1999. Ion binding and permeation through the lepidopteran amino acid transporter KAAT1 expressed in Xenopus oocytes. J. Physiol. 515:729-742

Busch, A., Waldegger, S., Herzer, T., Biber, J., Markovich, D., Hayes, G., Murer, H., Lang, F. 1994. Electrophysiological analysis of $\mathrm{Na}^{+} / \mathbf{P}_{\mathrm{i}}$ cotransport mediated by a transporter cloned from rat kidney and expressed in Xenopus oocytes. Proc. Natl. Acad. Sci. USA 91:8205-8208

Chenna, R., Sugawara, H., Koike, T., Lopez, R., Gibson, T.J., Higgins, D.G., Thompson, J.D. 2003. Multiple sequence alignment with the Clustal series of programs. Nucl Acids Res 31:3497-3500

Danisi, G., Murer, H., Straub, R.W. 1984. Effect of pH on phosphate transport into intestinal brush-border membrane vesicles. Am. J. Physiol. 246:G180-G186

de la Horra, C. de, Hernando, N., Lambert, G., Forster, I., Biber, J., Murer, H. 2000. Molecular determinants of $\mathrm{pH}$ sensitivity of the type IIa Na/P $\mathrm{P}_{\mathrm{i}}$ cotransporter. J. Biol. Chem. 275:6284-6287

Ehnes, C., Forster, I.C., Kohler, K., Bacconi, A., Stange, G., Biber, J., Murer, H. 2004. Structure-function relations of the first and fourth predicted extracellular linkers of the type IIa $\mathrm{Na}^{+} / \mathrm{Pi}$ cotransporter: I. Cysteine scanning mutagenesis. J. Gen. Physiol. 124:475-488

Elger, M., Werner, A., Herter, P., Kohl, B., Kinne, R.K., Hentschel, H. 1998. Na- $P_{i}$ cotransport sites in proximal tubule and collecting tubule of winter flounder (Pleuronectes americanus). Am. J. Physiol. 274:F374-F383

Feild, J.A., Zhang, L., Brun, K.A., Brooks, D.P., Edwards, R.M. 1999. Cloning and functional characterization of a sodiumdependent phosphate transporter expressed in human lung and small intestine. Biochem. Biophys. Res. Commun. 258:578-582

Forster, I., Hernando, N., Biber, J., Murer, H. 1998. The voltage dependence of a cloned mammalian renal type $\mathrm{II} \mathrm{Na}{ }^{+} / \mathrm{P}_{\mathrm{i}}$ cotransporter (NaPi-2). J. Gen. Physiol. 112:1-18

Forster, I.C., Biber, J., Murer, H. 2000. Proton-sensitive transitions of renal type II $\mathrm{Na}^{+}$-coupled phosphate cotransporter kinetics. Biophys. J. 79:215-230

Forster, I.C., Kohler, K., Biber, J., Murer, H. 2002a. Forging the link between structure and function of electrogenic cotransporters: The renal type $\mathrm{IIa} \mathrm{Na}{ }^{+} / \mathrm{P}_{\mathrm{i}}$ cotransporter as a case study. Prog. Biophys. Mol. Biol. 80:69-108

Forster, I.C., Kohler, K., Stange, G., Biber, J., Murer, H. 2002 b. Modulation of renal type $\mathrm{IIa} \mathrm{Na}^{+} / \mathrm{P}_{\mathrm{i}}$ cotransporter kinetics by the arginine modifier phenylglyoxal. J. Membr. Biol. 187:85-96

Forster, I.C., Loo, D.D., Eskandari, S. 1999. Stoichiometry and $\mathrm{Na}^{+}$binding cooperativity of rat and flounder renal type II $\mathrm{Na}^{+}-\mathrm{P}_{\mathrm{i}}$ cotransporters. Am. J. Physiol. 276:F644-F649

Forster, I.C., Wagner, C.A., Busch, A.E., Lang, F., Biber, J., Hernando, N., Murer, H., Werner, A. 1997. Electrophysiological 
characterization of the flounder type II $\mathrm{Na}^{+} / \mathrm{P}_{\mathrm{i}}$ cotransporter (NaPi-5) expressed in Xenopus laevis oocytes. J. Membr. Biol. 160:9-25

Frei, P., Gao, B., Hagenbuch, B., Mate, A., Biber, J., Murer, H., Meier, P.J., Stieger, B. 2005. Identification and localization of sodium-phosphate cotransporters in hepatocytes and cholangiocytes of rat liver. Am. J. Physiol. 288:G771-G778

Graham, C., Nalbant, P., Scholermann, B., Hentschel, H., Kinne, R.K., Werner, A. 2003. Characterization of a type IIb sodium-phosphate cotransporter from zebrafish (Danio rerio) kidney. Am. J. Physiol. 284:F727-F736

Gupta, A., Tenenhouse, H.S., Hoag, H.M., Wang, D., Khadeer, M.A., Namba, N., Feng, X., Hruska, K.A. 2001. Identification of the type II $\mathrm{Na}^{+}-\mathrm{P}_{\mathrm{i}}$ cotransporter $(\mathrm{Npt} 2)$ in the osteoclast and the skeletal phenotype of $\mathrm{Npt}^{-/-}$mice. Bone 29:467-476

Hartmann, C.M., Wagner, C.A., Busch, A.E., Markovich, D., Biber, J., Lang, F., Murer, H. 1995. Transport characteristics of a murine renal Na/Pi-cotransporter. Pfluegers Arch. 430:830-836

Hediger, M.A., Romero, M.F., Peng, J.B., Rolfs, A., Takanaga, H., Bruford, E.A. 2004. The ABCs of solute carriers: Physiological, pathological and therapeutic implications of human membrane transport proteins. Introduction. Pfluegers Arch. 447:465468

Hilfiker, H., Hattenhauer, O., Traebert, M., Forster, I., Murer, H., Biber, J. 1998. Characterization of a murine type II sodiumphosphate cotransporter expressed in mammalian small intestine. Proc. Natl. Acad. Sci. USA 95:14564-14569

Hisano, S., Haga, H., Li, Z., Tatsumi, S., Miyamoto, K.I., Takeda, E., Fukui, Y. 1997. Immunohistochemical and RTPCR detection of $\mathrm{Na}^{+}$-dependent inorganic phosphate cotransporter (NaPi-2) in rat brain. Brain Res. 772:149-155

Kohler, K., Forster, I.C., Stange, G., Biber, J., Murer, H. 2002. Identification of functionally important sites in the first intracellular loop of the NaPi-IIa cotransporter. Am. J. Physiol. 282:F687-F696

Krofchick, D., Huntley, S.A., Silverman, M. 2004. Transition states of the high-affinity rabbit $\mathrm{Na}^{+} /$glucose cotransporter SGLT1 as determined from measurement and analysis of voltage-dependent charge movements. Am. J. Physiol. 287:C46-C54

Lambert, G., Forster, I.C., Stange, G., Kohler, K., Biber, J., Murer, H. 2001. Cysteine mutagenesis reveals novel structurefunction features within the predicted third extracellular loop of the type IIa Na ${ }^{+} / \mathrm{P}_{\mathrm{i}}$ cotransporter. J. Gen. Physiol. 117:533-546

Mager, S., Cao, Y., Lester, H.A. 1998. Measurement of transient currents from neurotransmitter transporters expressed in Xenopus oocytes. Methods Enzymol. 296:551-566

Mager, S., Naeve, J., Quick, M., Labarca, C., Davidson, N., Lester, H.A. 1993. Steady states, charge movements, and rates for a cloned GABA transporter expressed in Xenopus oocytes. Neuron 10:177-188

Murer, H., Forster, I., Biber, J. 2004. The sodium phosphate cotransporter family SLC34. Pfluegers Arch. 447:763-767

Murer, H., Hernando, N., Forster, I., Biber, J. 2000. Proximal tubular phosphate reabsorption: Molecular mechanisms. Physiol. Rev. 80:1373-1409
Nalbant, P., Boehmer, C., Dehmelt, L., Wehner, F., Werner, A. 1999. Functional characterization of a $\mathrm{Na}^{+}$-phosphate cotransporter (NaPi-II) from zebrafish and identification of related transcripts. J. Physiol. 520:79-89

Ohkido, I., Segawa, H., Yanagida, R., Nakamura, M., Miyamoto, K. 2003. Cloning, gene structure and dietary regulation of the type-IIc $\mathrm{Na} / \mathrm{Pi}$ cotransporter in the mouse kidney. Pfluegers Arch. 446:106-115

Radanovic, T., Murer, H., Biber, J. 2003. Expression of the Na/ $\mathbf{P}_{\mathrm{i}}$ cotransporter type IIb in Sf9 cells: Functional characterization and purification. J. Membr. Biol. 194:91-96

Radanovic, T., Wagner, C.A., Murer, H., Biber, J. 2005. Regulation of intestinal phosphate transport. I. Segmental expression and adaptation to low-Pi diet of the type IIb $\mathrm{Na}^{+}$-Pi cotransporter in mouse small intestine. Am. J. Physiol. 288:G496-G500

Segawa, H., Kaneko, I., Takahashi, A., Kuwahata, M., Ito, M., Ohkido, I., Tatsumi, S., Miyamoto, K. 2002. Growth-related renal type II Na/Pi cotransporter. J. Biol. Chem. 277:1966519672

Virkki, L.V., Forster, I.C., Bacconi, A., Biber, J., Murer, H. 2005a. Functionally important residues in the predicted 3rd transmembrane domain of the type IIa sodium-phosphate co-transporter (NaPi-IIa). J. Membr. Biol. 206:227-238

Virkki, L.V., Forster, I.C., Biber, J., Murer, H. 2005b. Substrate interactions in the human type IIa sodium-phosphate cotransporter (NaPi-IIa). Am. J. Physiol. 288:F969-F981

Virkki, L.V., Murer, H., Forster, I.C. 2006a. Voltage clamp fluorometric measurements on a type II $\mathrm{Na}^{+}$-coupled $\mathrm{P}_{\mathrm{i}}$ cotransporter: Shedding light on substrate binding order. J. Gen. Physiol. 127:539-555

Virrki, L.V., Murer, N., Forster, I.C. 2006b. Mapping conformational changes of a type IIb $\mathrm{Na}^{+} / \mathrm{Pi}$ cotransporter by voltage clamp fluorometry. J. Biol. Chem. 281:28837-28849

Wadiche, J.I., Arriza, J.L., Amara, S.G., Kavanaugh, M.P. 1995. Kinetics of a human glutamate transporter. Neuron 14:10191027

Werner, A., Dehmelt, L., Nalbant, P. 1998. $\mathrm{Na}^{+}$-dependent phosphate cotransporters: The NaPi protein families. J. Exp. Biol. 201:3135-3142

Werner, A., Kinne, R.K. 2001. Evolution of the Na- $\mathrm{P}_{\mathrm{i}}$ cotransport systems. Am. J. Physiol. 280:R301-R312

Xu, H., Inouye, M., Missey, T., Collins, J.F., Ghishan, F.K. 2002. Functional characterization of the human intestinal NaPi-IIb cotransporter in hamster fibroblasts and Xenopus oocytes. Biochim. Biophys. Acta 1567:97-105

Xu, Y., Yeung, C.H., Setiawan, I., Avram, C., Biber, J., Wagenfeld, A., Lang, F., Cooper, T.G. 2003. Sodium-inorganic phosphate cotransporter NaPi-IIb in the epididymis and its potential role in male fertility studied in a transgenic mouse model. Biol. Reprod. 69:1135-1141

Zampighi, G.A., Kreman, M., Boorer, K.J., Loo, D.D., Bezanilla, F., Chandy, G., Hall, J.E., Wright, E.M. 1995. A method for determining the unitary functional capacity of cloned channels and transporters expressed in Xenopus laevis oocytes. J. Membr. Biol. 148:65-78 